\title{
Phosphate and Feldspar Mineralogy of Equilibrated L Chondrites: The Record of Metasomatism During Metamorphism in Ordinary Chondrite Parent Bodies
} DOI:

10.1111/maps.12719

\section{Document Version \\ Accepted author manuscript}

Link to publication record in Manchester Research Explorer

Citation for published version (APA):

Lewis, J. A., \& Jones, R. (2016). Phosphate and Feldspar Mineralogy of Equilibrated L Chondrites: The Record of Metasomatism During Metamorphism in Ordinary Chondrite Parent Bodies. Meteoritics and Planetary Science. https://doi.org/10.1111/maps.12719

\section{Published in:}

Meteoritics and Planetary Science

\section{Citing this paper}

Please note that where the full-text provided on Manchester Research Explorer is the Author Accepted Manuscript or Proof version this may differ from the final Published version. If citing, it is advised that you check and use the publisher's definitive version.

\section{General rights}

Copyright and moral rights for the publications made accessible in the Research Explorer are retained by the authors and/or other copyright owners and it is a condition of accessing publications that users recognise and abide by the legal requirements associated with these rights.

\section{Takedown policy}

If you believe that this document breaches copyright please refer to the University of Manchester's Takedown Procedures [http://man.ac.uk/04Y6Bo] or contact uml.scholarlycommunications@manchester.ac.uk providing relevant details, so we can investigate your claim.

\section{OPEN ACCESS}




\section{Phosphate and Feldspar Mineralogy of Equilibrated $\mathbf{L}$ Chondrites: The Record of Metasomatism During Metamorphism in Ordinary Chondrite Parent Bodies}

\begin{tabular}{|c|c|}
\hline Journal: & Meteoritics \& Planetary Science \\
\hline Manuscript ID & MAPS-2496.R2 \\
\hline Manuscript Type: & Article \\
\hline Date Submitted by the Author: & $\mathrm{n} / \mathrm{a}$ \\
\hline Complete List of Authors: & $\begin{array}{l}\text { Lewis, Jonathan; University of New Mexico, Department of Earth and } \\
\text { Planetary Sciences } \\
\text { Jones, Rhian; University of New Mexico, Department of Earth and Planetary } \\
\text { Sciences; University of Manchester, School of Earth, Atmospheric and } \\
\text { Environmental Sciences }\end{array}$ \\
\hline Keywords: & metamorphism < Thermal, Feldspar, Metasomatism, Phosphates \\
\hline \multicolumn{2}{|c|}{$\begin{array}{l}\text { Note: The following files were submitted by the author for peer review, but cannot be converted to } \\
\text { PDF. You must view these files (e.g. movies) online. }\end{array}$} \\
\hline Supporting_information.xls & \\
\hline
\end{tabular}

\section{SCHOLARONE ${ }^{\text {m }}$}

Manuscripts 
Phosphate and Feldspar Mineralogy of Equilibrated L Chondrites:

The Record of Metasomatism During Metamorphism in Ordinary Chondrite Parent Bodies

Jonathan A. Lewis ${ }^{1}$ and Rhian H. Jones ${ }^{1,2}$

${ }^{1}$ Department of Earth and Planetary Sciences, University of New Mexico, Albuquerque, NM 87131

${ }^{2}$ School of Earth, Atmospheric and Environmental Sciences, University of Manchester, Manchester, M13 9PL, UK

Submitted to MAPS, January 6, 2016

Revised May 9, 2016

Revised June 7, 2016

\begin{abstract}
$\underline{\text { Abstract }}$
In ordinary chondrites (OCs), phosphates and feldspar are secondary minerals known to be products of parent body metamorphism. Both minerals provide evidence that metasomatic fluids played a role during metamorphism. We studied the petrology and chemistry of phosphates and feldspar in petrologic type 4-6 L chondrites, to examine the role of metasomatic fluids, and to compare metamorphic conditions across all three OC groups. Apatite in L chondrites is $\mathrm{Cl}$-rich, similar to $\mathrm{H}$ chondrites, whereas apatite in LL chondrites has lower $\mathrm{Cl} / \mathrm{F}$ ratios. Merrillite has similar compositions among the three chondrite groups. Feldspar in L chondrites shows a similar equilibration trend to LL chondrites, from a wide range of plagioclase compositions in petrologic type 4 to a homogeneous albitic composition in type 6. This contrasts with $\mathrm{H}$ chondrites which have homogeneous albitic plagioclase in petrologic types 4-6. Alkali- and halogen-rich and likely hydrous metasomatic fluids acted during prograde metamorphism on OC parent bodies, resulting in albitization reactions and development of phosphate minerals. Fluid compositions transitioned to a more anhydrous, Cl-rich composition after the asteroid began to cool. Differences in secondary minerals between $\mathrm{H}$ and L, LL chondrites can be explained by differences in fluid abundance, duration, or timing of fluid release. Phosphate minerals in the regolith breccia, Kendleton, show lithology-dependent apatite compositions. Bulk Cl/F ratios for OCs inferred from apatite compositions are higher than measured bulk chondrite values, suggesting that bulk $\mathrm{F}$ abundances are overestimated and that bulk $\mathrm{Cl} / \mathrm{F}$ ratios in OCs are similar to $\mathrm{CI}$.

Introduction

Ordinary chondrites (OCs) show a sequence of equilibration of both textural and chemical characteristics. These changes are described by petrologic types 3-6 and are generally accepted to represent progressive degrees of metamorphism which occur within 65 million years after accretion (Van Schmus and Wood 1967; Huss et al. 2006). Textural changes include recrystallization of the matrix, crystallization of chondrule mesostasis, blurring of the chondrule-matrix texture, and growth of secondary phases. Olivine and pyroxene show a wide range of compositions in type 3. Due to differences in the MgFe interdiffusion rate for olivine and pyroxene, equilibration in olivine occurs by petrologic type 4 followed by pyroxene which is equilibrated by type 5 .

The metamorphic environment on OC parent bodies is only poorly constrained and peak temperatures are only roughly defined. Peak temperatures for petrologic type 3 are not thought to exceed $500{ }^{\circ} \mathrm{C}$, types $4-5$ range from $500-800^{\circ} \mathrm{C}$, and type 6 from $800^{\circ} \mathrm{C}$ to the onset of melting at $\sim 1000{ }^{\circ} \mathrm{C}$ (Scott and Krot 2014). Additionally, although the presence of fluids has been inferred from mineralogical observations, the importance of fluids and their role during metamorphism is still poorly understood. Low petrologic type chondrites show evidence for the action of fluids from the presence of phyllosilicates (Alexander et al. 1989), carbide-magnetite assemblages (Krot et al. 1997), sulfide-magnetite assemblages (Huss 1979), and bleached chondrules (Grossman et al. 2000). Increases in Fe oxidation (McSween and Labotka 1993) and possible mixing of O-isotope reservoirs (Bridges et al. 1999) are indication of fluid activity in the higher petrologic types.
\end{abstract}


Secondary minerals that occur as a result of thermal metamorphism can be used to understand the environment in which they form and evolve. Specifically, phosphate minerals and feldspar can preserve a record of any fluids present, and feldspar microstructures are a sensitive indicator of thermal history. Two phosphate minerals are present in petrologic type 4-6 ordinary chondrites: apatite $\left(\mathrm{Ca}_{5}\left(\mathrm{PO}_{4}\right)_{3} \mathrm{X}\right.$, where $\mathrm{X}$ represents monovalent anions, typically $\mathrm{Cl}^{-}, \mathrm{F}^{-}$or $\left.\mathrm{OH}^{-}\right)$and merrillite $\left(\mathrm{Na}_{2}\left(\mathrm{Mg}, \mathrm{Fe}^{2+}\right)_{2} \mathrm{Ca}_{18}\left(\mathrm{PO}_{4}\right)_{14}\right)$ (Brearley and Jones 1998). In the traditional view of metamorphism, phosphates are considered to form in a solid-state oxidation reaction, with $\mathrm{P}$ derived from its primary occurrence in Fe,Ni metal (Ahrens 1970; Jones et al. 2014). Feldspar is typically albitic in composition and generally is considered to form from the crystallization of chondrule mesostasis by petrologic type 4, with progressive coarsening to type 6 (Van Schmus and Wood 1967).

Previous studies of LL and $\mathrm{H}$ chondrites reveal histories involving fluid interactions, for both phosphates (Jones and McCubbin 2012; Jones et al. 2014) and feldspar (Kovach and Jones 2010). Jones et al. (2014) showed that apatite in LL chondrites has high $\mathrm{Cl} / \mathrm{F}$ ratios and $\mathrm{H}_{2} \mathrm{O}$ abundances less than 100 $\mathrm{ppm}$. Due to the lack of apatite equilibration with increasing petrologic type they argue for the presence of a dry, Cl-rich fluid acting after peak metamorphism. Apatite in $\mathrm{H}$ chondrites was found to be similar, although with slightly higher $\mathrm{Cl} / \mathrm{F}$ ratios than LL chondrites (Jones and McCubbin 2012). Kovach and Jones (2010) showed that a wide range of plagioclase feldspar compositions is present in petrologic type 4 LL chondrites which equilibrate to an albitic composition $\left(\sim \mathrm{An}_{12}\right)$ by petrologic type 6 . LL chondrites also show evidence for alkali metasomatism where interaction with $\mathrm{Na}$ - and K-bearing fluids result in albitization reactions, and uptake of $\mathrm{K}$ in feldspar that later exsolves. In contrast, Kovach and Jones (2010) showed that $\mathrm{H}$ chondrites have homogeneous plagioclase compositions in types 4-6, indicating that equilibration occurred in petrologic type 3, i.e. at lower peak temperatures than in the LL chondrites. Currently, it is not clear how the L chondrites compare with the H and LL chondrites, and whether they show similarities to either of these groups. In this study, we extend these previous findings to examine the behavior of phosphates and feldspar in L chondrites, in order to compare the metamorphic and metasomatic histories of all three ordinary chondrite groups and to assess similarities and differences among the ordinary chondrite parent bodies.

\section{Samples \& Analytical Methods}

We studied both phosphates and feldspar in three equilibrated ordinary chondrites: Santa Barbara (L4), Elenovka (L5), and Bruderheim (L6) (Fig. 1a-c). We also analyzed phosphates in the regolith breccia Kendleton (L3-5) (Fig. 1d-f) and feldspar in Kramer Creek (L4) and Roy 1933 (L5) (Table 1). Kramer Creek and Roy 1933 are finds with low degrees of terrestrial weathering, W3 and W2 respectively, which we determined using the method of Wlotzka (1993). The other four chondrites are falls and were chosen in order to minimize the effects of terrestrial weathering. Low to moderate shock stages have been reported for Kramer Creek (S2), Roy 1933 (S3), Elenovka (S3) and Bruderheim (S4) (Stöffler et al. 1991; Rubin 2004). Santa Barbara was also determined to have a low shock stage (S2) during the course of this study according to the method described by Stöffler et al. (1991). Kendleton is a regolith breccia with an L4 chondritic host, clasts of L3 and L5 material, areas of shock darkening, and shock melt veins (Ehlmann et al. 1988). Despite these shock features, the material we studied only has low to moderate reported shock stages of $\sim \mathrm{S} 3$ for the L3 clast and L4 host and $\sim \mathrm{S} 2$ for the L5 clast (Ehlmann et al. 1988; Rubin 2004).

Phosphate and feldspar grains were located in each thin section using optical microscopy, and scanning electron microscopy (SEM). We used a JEOL 5800 SEM and a FEI Quanta 3D field emission gun SEM for backscattered electron (BSE) imaging and energy-dispersive spectroscopic (EDS) analysis. Quantitative wavelength-dispersive spectroscopic (WDS) analysis was conducted on a JEOL 8200LV electron probe microanalyzer (EPMA) with a $15 \mathrm{kV}$ accelerating voltage and $20 \mathrm{nA}$ beam current. Phosphates were analyzed with a $5 \mu \mathrm{m}$ spot using the following standards: Taylor apatite (Ca, P, F), Taylor olivine $(\mathrm{Mg}, \mathrm{Fe})$, sodalite $(\mathrm{Cl}, \mathrm{Na})$, Y-phosphate $(\mathrm{Y})$, and Ce-phosphate $(\mathrm{Ce})$. We also used a second apatite standard, FM020, for Ca and P (McCubbin et al. 2012). We used the live chart recorder to monitor $\mathrm{F}$ and $\mathrm{Cl}$ count rates during the analyses to ensure migration was not occurring, particularly in $\mathrm{F}$ 
(Stormer et al. 1993; McCubbin et al. 2010) and F was analyzed using the LDE crystal spectrometer. Feldspar grains were analyzed with a 2-10 $\mu \mathrm{m}$ beam diameter using the following Taylor standards: albite ( $\mathrm{Si}, \mathrm{Al}, \mathrm{Na})$, orthoclase $(\mathrm{Al}, \mathrm{K})$, diopside $(\mathrm{Ca}, \mathrm{Si})$, olivine $(\mathrm{Fe}, \mathrm{Mg})$, and chromite $(\mathrm{Cr})$.

Phosphate abundances and distribution maps were generated from combined WDS/EDS element maps for each thin section using the electron microprobe (Fig. 1). Maps were obtained over a $10 \mathrm{~mm}$ x 10 $\mathrm{mm}$ area for Santa Barbara, Elenovka, and Bruderheim, a $5 \mathrm{~mm}$ x $15 \mathrm{~mm}$ area for the Kendleton L4 host, a $5 \mathrm{~mm} \times 5 \mathrm{~mm}$ area for the L3 clast, and a $5 \mathrm{~mm} \times 10 \mathrm{~mm}$ area for the L5 clast. The maps were generated with a step size of $10 \mu \mathrm{m} / \mathrm{px}$ with a $20 \mathrm{~ms}$ dwell time per pixel and a $10 \mu \mathrm{m}$ wide electron beam. We determined modal abundances by pixel counting in Adobe Photoshop. The total phosphate abundance was calculated by counting pixels containing both $\mathrm{P}$ and $\mathrm{Ca}$ above a $25 \%$ threshold. Apatite abundance was then calculated by counting phosphate pixels with $\mathrm{Cl}$ above a $10 \%$ threshold and merrillite was determined by difference. Volume percentages were calculated as an area since no fabric was noted on any of the samples. Uncertainty in phosphate abundances are estimated to be $\pm 0.1 \%$ by volume, absolute. This uncertainty is estimated by varying the thresholding parameters by $\pm 10 \%$ and is consistent with the uncertainty estimated for phosphate abundances in LL chondrites by Jones et al. (2014) using a similar thresholding technique.

Phosphate distribution maps were also used to determine maximum and average grain sizes for apatite and merrillite using particle analysis in ImageJ. Individual grain sizes were taken to be the maximum dimension (width or height) produced by the particle analysis. Maximum grain sizes measured in this manner are very close to sizes of the largest grains measured in BSE images. For example, the large merrillite grain in Kendleton's L5 clast (Fig. 4e) is approximately $400 \mu \mathrm{m}$ x $650 \mu \mathrm{m}$ in size and the particle analysis yields a grain size of $620 \mu \mathrm{m}$. However, since the phosphate map resolution is $10 \mu \mathrm{m} / \mathrm{px}$, average grain sizes are inevitably biased by grains greater than or equal to $10 \mu \mathrm{m}$. Maximum grain sizes are likely much more accurate than the averages.

\section{$\underline{\text { Results }}$}

\section{Phosphates}

\section{Abundances \& Distribution}

Phosphate abundances and grain sizes are summarized in Table 2 and illustrated in Figure 1. Apatite and merrillite appear to have a homogeneous and random distribution throughout the mapped areas of Elenovka and Bruderheim. Santa Barbara has an increase in phosphate abundance and average size from the lower left to the upper right of the thin section (Fig. 1a). This change in texture does not appear to correspond with any obvious differences in thin section texture. Total phosphate volume percentages are 0.4\%, 0.7\%, and 0.5\% for Santa Barbara, Elenovka, and Bruderheim respectively. Merrillite is more common than apatite in Elenovka and Bruderheim, but in Santa Barbara phosphates are approximately equal in abundance (49\% apatite to $51 \%$ merrillite). Average apatite grain sizes are larger than merrillite by nearly a factor of 2 though size distributions for both phosphates are very broad and dominated by small grains. Average grain sizes in Santa Barbara, Elenovka, and Bruderheim are $58 \mu \mathrm{m}$, $62 \mu \mathrm{m}$, and $55 \mu \mathrm{m}$ for apatite and $30 \mu \mathrm{m}, 35 \mu \mathrm{m}$, and $31 \mu \mathrm{m}$ for merrillite respectively. The largest merrillite grains are 10-30\% larger than the largest apatite grains. Maximum grain sizes for Santa Barbara, Elenovka, and Bruderheim are $230 \mu \mathrm{m}, 390 \mu \mathrm{m}$, and $400 \mu \mathrm{m}$ for apatite and $290 \mu \mathrm{m}, 490 \mu \mathrm{m}$, and $390 \mu \mathrm{m}$ for merrillite respectively.

In the regolith breccia Kendleton we focused on an L3 clast $\sim 5 \mathrm{~mm}$ in diameter present within an impact melt vein (Fig. 1d), the L4 host (Fig. 1e) which comprises $\sim 80 \%$ of the material (Ehlmann et al. 1988), and an L5 clast $\sim 20 \mathrm{~mm}$ in diameter (Fig. 1f). Kendleton also has a largely homogeneous and random distribution of phosphates in the mapped areas. However, the L5 clast is dominated by a single large (approximately $400 \mu \mathrm{m} \times 650 \mu \mathrm{m}$ ) apatite-bearing merrillite grain (Fig. 1f). This is the largest grain we observed in any sample and its presence skews the phosphate abundance and grain size distribution for this clast. The L3 clast and L4 host have comparatively low phosphate abundances of $0.2 \%$ and $0.3 \%$ 
respectively while the L5 clast has a much larger phosphate abundance of $0.7 \%$. Apatite abundances in Kendleton's L3 and L5 clasts are similar to the other samples, $46 \%$ and 37\% of the total phosphate respectively. However, the L4 host has an extremely low apatite abundance of $3 \%$ of the total phosphate. Apatite grain size is also small in the L4 host with an average size of $28 \mu \mathrm{m}$ and the largest grain only 60 $\mu \mathrm{m}$, whereas merrillite has a larger average and maximum grain size of $40 \mu \mathrm{m}$ and $280 \mu \mathrm{m}$ respectively. The L3 clast has larger average and maximum grain sizes for apatite ( $39 \mu \mathrm{m}$ and $160 \mu \mathrm{m}$ respectively) than merrillite ( $20 \mu \mathrm{m}$ and $80 \mu \mathrm{m}$ respectively) though the counting statistics are poor because of the small size of the clast. The L5 clast on the other hand has a larger average and maximum grain size for merrillite ( $45 \mu \mathrm{m}$ and $620 \mu \mathrm{m}$ respectively) than apatite ( $42 \mu \mathrm{m}$ and $290 \mu \mathrm{m}$ respectively) due to the single large grain of merrillite.

Although the low abundance of apatite in the Kendleton L4 host does somewhat reflect its sparse distribution (Fig. 1d), our abundance value may be exaggerated by a known bias in our method of calculating abundances. The defocused, $10 \mu \mathrm{m}$ beam integrates signal over the full $10 \mu \mathrm{m}$ area, causing smaller grains to get lost in the signal of larger or more numerous grains. The phosphate minerals in the L4 host are generally quite small so may be subject to this analytical effect. Additionally, $\mathrm{Cl}$ has a relatively weak signal compared to $\mathrm{P}$ and $\mathrm{Ca}$. The $\mathrm{Cl}$ signal also has a large amount of noise due to small amounts of $\mathrm{Cl}$ present in the epoxy used to mount the thin section. As a result, small-scale intergrowths of apatite and merrillite, also common in the L4 host, may be recognized primarily as merrillite. As the phosphate grains grow in size and compositional distinction, as seen in Elenovka and Bruderheim, this bias is significantly reduced.

\section{Petrography}

\section{Santa Barbara (L4)}

Small grains of apatite are highly fractured (Fig. 2a,b) while larger grains are typically much smoother. In general, merrillite is less fractured than apatite (Fig. 3a,b). Neither phosphate mineral has a preferred silicate association and both occur adjacent to olivine, pyroxene, and feldspar (Fig. 2a,b, 3a,b). Both merrillite and apatite commonly contain silicate inclusions which are predominantly olivine and feldspar (e.g. Fig. 3a) and only rarely pyroxene. Both apatite and merrillite also occur commonly in association with large grains of Fe,Ni metal, sulfides, and chromite (e.g. Fig. 3b). The two phosphates do not occur together with the exception of a single $100 \mu \mathrm{m}$ grain in which apatite and merrillite are intergrown (Fig. 2b).

\section{Elenovka (L5)}

Fracturing is pervasive in apatite (Fig. 2c,d) but much less common in merrillite (Fig. 3c). Apatite is commonly found adjacent to or surrounding voids (Fig. 2c,d). It is not clear if these voids are original or the result of sample preparation in which grains of apatite (or grains adjacent to apatite, such as $\mathrm{Fe}, \mathrm{Ni}$ metal) are preferentially lost during the polishing process. Merrillite occurs frequently adjacent to $\mathrm{Fe}, \mathrm{Ni}$ metal and sulfides (Fig. 3c), though like Santa Barbara, there is no preferential association with a single silicate phase. Olivine, pyroxene, and small grains of feldspar occur adjacent to both apatite and merrillite. Inclusions in merrillite are almost exclusively olivine and feldspar. Figure $3 \mathrm{~d}$ shows two such inclusions: a $10 \mu \mathrm{m}$ olivine inclusion and a $2 \mu \mathrm{m}$ feldspar inclusion.

\section{Bruderheim (L6) \\ Apatite is only lightly to moderately fractured (Fig. 2e,f). Fig. $2 \mathrm{f}$ illustrates possible crystallographic control to the fractures. Merrillite is generally smooth (Fig. 3e). Apatite is commonly found near voids (Fig. 2e) and merrillite occurs in contact with Fe,Ni metal (Fig. 3e) and sulfides. Olivine, pyroxene, and feldspar are common minerals in association with the phosphates. Olivine and feldspar are other common inclusions in both merrillite and apatite (Fig. 2e, 3f). In the assemblage illustrated in Fig. 3f, feldspar surrounds merrillite and also contains abundant, fine-grained chromite. Chromite inclusions are also present within the merrillite.}




\section{Kendleton (L3 clast)}

Apatite and merrillite occur in association with recrystallized feldspathic mesostasis within chondrules (Fig. 4a) and outside chondrules in association with fine-grained matrix. Merrillite is also commonly associated with Fe,Ni metal (Table 2, Fig. 4b). Fig. 4b shows multiple merrillite inclusions within $\mathrm{Fe}, \mathrm{Ni}$ metal where merrillite is surrounded by Ni-rich halos. Ni-enrichment may have occurred during merrillite grain growth during which $\mathrm{Fe}$ was removed from the metal and incorporated into the phosphate. This particular metal grain is located close to the impact melt vein and may have been influenced by the vein's formation.

\section{Kendleton (L4 host)}

Phosphates in Kendleton's L4 host differ substantially from Santa Barbara, Elenovka, and Bruderheim. Merrillite dominates the phosphates, accounting for 97\% (Table 2). Unlike L4 Santa Barbara (Figs. 2a,b and 3a,b), merrillite and apatite in the Kendleton L4 material commonly occur together, with a texture suggesting apatite is replacing the merrillite (Fig. 4c). Both apatite and merrillite are only moderately fractured. Apatite also commonly occurs as small grains in the matrix or along cracks (Fig. 4d). Individual merrillite grains tend to be small and can occur in chains of small, interconnected grains or as inclusions within Fe,Ni metal, similar to the inclusions seen in the L3 clast (Fig. 4b).

\section{Kendleton (L5 clast)}

The large phosphate assemblage in the L5 clast consists of a large merrillite grain with intergrown apatite. The merrillite has numerous feldspar and olivine inclusions but few pyroxene inclusions. Apatite and merrillite also occur together in other grains (e.g. Fig. 4f) with textures intermediate to the replacement texture seen in the L4 host (Fig. 4c) and the intergrowth seen in Santa Barbara (Fig. 2d).

\section{Compositions}

Average apatite compositions in each chondrite are summarized in Table 3 and individual analyses are presented in Table S1. The apatite formula was calculated with 13 anions. OH values were calculated by difference assuming the X-site anions summed to unity, and were not added to the formula totals. Apatite is generally chlorine rich with average atomic $\mathrm{Cl} / \mathrm{F}$ ratios of $6.6,6.1$, and 5.0 for Santa Barbara, Elenovka, and Bruderheim respectively. Kendleton's L3 and L5 clasts have similar atomic Cl/F ratios of 5.5 and 4.7 respectively. However, apatite in Kendleton's L4 host has a much higher F content $(1.1 \mathrm{wt} \%)$ than the other chondrites (0.4-0.6 wt\%), and a significantly lower atomic $\mathrm{Cl} / \mathrm{F}$ ratio of 1.9 . Figure 5 illustrates the anion distribution in apatite. The third apex of the apatite ternary (after $\mathrm{Cl}$ and $\mathrm{F}$ ) is typically reserved for $\mathrm{OH}$. However, Jones et al. (2014) measured apatite $\mathrm{H}_{2} \mathrm{O}$ abundance in type 4-6 LL chondrites using SIMS analysis and found the values to be extremely low, less than $100 \mathrm{ppm}$. The balance of the $\mathrm{X}$ anion site remains unidentified and so we label the third apex "other."

Apatite compositions in Santa Barbara, Elenovka, and Bruderheim show considerable overlap with a mean atomic $\mathrm{Cl} / \mathrm{F}$ ratio of 5.9 for all the analyses in these three meteorites. Although there is a slight correlation between the mean $\mathrm{Cl} / \mathrm{F}$ ratio and petrologic type, it is not clear that this is due to changes that occur during metamorphism. Applying a t-test to the three mean $\mathrm{Cl} / \mathrm{F}$ ratios only reveals a significant difference between Santa Barbara and Bruderheim. Additionally, there is no evidence for progressive compositional equilibration with petrologic type.

Average compositions of merrillite in each chondrite are summarized in Table 4 and Figure 6 and individual analyses are presented in Table S2: the merrillite formula is calculated assuming 56 oxygens. The resulting formulae are close to ideal with little deviation. Santa Barbara has an average Mg\# of 85 and a much larger spread in values than Elenovka or Bruderheim which both have an average Mg\# of 92 . The average Mg\# of the L3 clast is 93 and with little spread, although this could be due to the small number of analyses. Similar to Santa Barbara, Kendleton's L4 host has a significant spread and Mg\# of 90. Like the other high petrologic types Elenovka and Bruderheim, the average Mg\# of Kendleton's L5 
clast is 92 with a small spread. Figure 6 also shows merrillite distributions for H (Jones and McCubbin 2012) and LL (Jones et al. 2014) chondrites of petrologic types 4, 5 and 6 for comparison with the L data, discussed below.

\section{Feldspar}

In this study, we focused on feldspar within chondrules, which is largely formed from the devitrification of chondrule mesostasis and should share a similar history of development throughout the chondrite. We do not consider feldspar found within the chondrite matrix, because limiting our observations to chondrule-hosted feldspar allows for a direct comparison with the similar study conducted on H and LL chondrites by Kovach and Jones (2010).

\section{Petrography}

Santa Barbara (L4)

Feldspar in Santa Barbara chondrules is typically present interstitial to the olivine and pyroxene phenocrysts. It has an irregular, space-filling morphology and appears to represent recrystallized mesostasis (Fig. 7a). Most feldspar grains are $<20 \mu \mathrm{m}$ in size although some range up to $100 \mu \mathrm{m}$. The majority of the feldspar grains have inclusions of micron-sized clinopyroxene and abundant micron and submicron inclusions of oxides (typically chromite) and sulfides (Fig. 7b). Micropores are also abundant. Anorthitic feldspar is commonly observed being replaced by albitic feldspar, particularly around grain boundaries (Fig. 7b). In these instances, the albite is smooth and largely inclusion free while the anorthite contains numerous oxides and micropores. In other chondrules, all feldspar is albitic. Regions of smooth albite occasionally contain fine-scale K-feldspar exsolution lamellae (Fig. 7d).

\section{Kramer Creek (L4)}

Like L4 Santa Barbara, feldspar in Kramer Creek is typically irregular in shape and intergrown with elongate grains of pyroxene and olivine. Micron-sized oxides are present in many feldspar grains but are not as abundant as in Santa Barbara. Porosity is common in both anorthitic and albitic feldspar. Anorthitic feldspar is commonly replaced by albite along grain boundaries (Fig. 7f) in a similar manner to, but less extensively than, Santa Barbara (Fig. 7b). Generally, feldspar grains are small $(<30 \mu \mathrm{m})$, but they can range up to $100 \mu \mathrm{m}$. Terrestrial weathering does not appear to have affected the feldspar texture.

\section{Elenovka (L5)}

In Elenovka, smooth, inclusion-free albitic feldspar is common. Grain sizes vary within chondrules but are generally larger than Santa Barbara and Kramer Creek, $>30 \mu \mathrm{m}$ with some $>100 \mu \mathrm{m}$. Individual feldspar grains vary from subhedral to irregular and are space-filling in morphology (Fig. 7g). Unlike in Santa Barbara and Kramer Creek, we did not observe feldspar grains that are porous in texture nor did they contain many fine-grained oxide inclusions. In a few chondrules, feldspar is included within irregular grains of pyroxene, where it is assumed to be recrystallized mesostasis. Some grains show minor exsolution of K-feldspar in albitic host grains (Fig. 7h).

\section{Roy 1933 (L5)}

Feldspar in Roy 1933 varies in size but is generally similar to Elenovka. Individual feldspar grain textures vary from anhedral to subhedral and many have irregular morphologies. A few feldspar grains are porous in texture, or contain fine-grained oxide/sulfide inclusions. In many chondrules, feldspar is intergrown with elongate grains of olivine, and is assumed to be recrystallized mesostasis. Like L5 Elenovka (Fig. 7h), rare exsolution of K-feldspar is present in host grains of albitic feldspar (Fig. 7j).

\section{Bruderheim (L6)}

Bruderheim contains very few well-defined relict chondrules, and chondrule/matrix boundaries are not very distinct. However, it was possible to identify individual feldspar grains in relict chondrules 
(Fig. 7k) with a range of sizes slightly greater than in the type 5 chondrites. Most are $>30 \mu \mathrm{m}$ and they can be larger than $150 \mu \mathrm{m}$. Some grains contain a few fine-grained chromite and sulfide inclusions. Individual grain textures vary from anhedral to subhedral, and include many feldspar grains with irregular morphologies. Similar to type 5, feldspar grains are intergrown with elongate grains of pyroxene and irregular grains of olivine, but in Bruderheim, the grains in these areas are larger and more abundant (Fig. 71). We observed no K-feldspar.

\section{Compositions}

Average feldspar compositions are summarized in Table 5 and individual point analyses are tabulated in Table S3 and illustrated on feldspar ternary diagrams in Fig. 8 and tabulated in Table S3. The L4 chondrites Santa Barbara and Kramer Creek (Fig. 8a, 8b) show a wide range of plagioclase compositions, $\mathrm{An}_{82}-\mathrm{An}_{4}$ and $\mathrm{An}_{88}-\mathrm{An}_{2}$ respectively. Each chondrule typically has a limited range of compositions, although those with albitization reactions (e.g. Santa Barbara chondrule 4, shown in Fig. 7b) show both An-rich and Ab-rich components. Kramer Creek has the widest range of plagioclase compositions and the lowest Or component which does not exceed $\mathrm{Or}_{3}$. Santa Barbara feldspar has a larger range of $\mathrm{K}$ contents, up to $\mathrm{Or}_{23}$. High $\mathrm{K}$ contents are measured in grains that show fine-scale $\mathrm{K}$ feldspar exsolution, and represent analyses that overlap albitic and K-feldspar compositions within those grains.

The L5 chondrites Elenovka and Roy 1933 show a much more restricted range in plagioclase compositions, $\mathrm{An}_{12}-\mathrm{An}_{8}$ and $\mathrm{An}_{17}-\mathrm{An}_{4}$ respectively, compared to the $\mathrm{L} 4$ chondrites. Both have grains that show K-feldspar exsolution, although only the grains in Roy 1933 chondrule 7 (Fig. 7j) are large enough for individual microprobe analysis: these have Or content up to $\mathrm{Or}_{65}$. The highest Or content measured in Elenovka was only $\mathrm{Or}_{13}$ which represents the bulk composition of the grain, due to the fine-scale nature of the exsolution lamellae. Feldspar in the L6 Bruderheim is fully equilibrated with an average composition of $\mathrm{An}_{10} \mathrm{Ab}_{84} \mathrm{Or}_{6}$ and very little variation.

\section{Discussion}

Thermal metamorphism is one of the most important processes that affected the evolution of ordinary chondritic asteroids. Although there is some evidence for metasomatizing fluids on OC parent bodies, the extent of fluid interactions is poorly described. Because the presence of fluids can strongly affect the metamorphic environment, characterizing these fluids is essential for a complete understanding of chondrite metamorphism. In addition, characterizing volatile species present within chondritic asteroids provides important information about the volatile composition of the solar nebula from which the Earth and other terrestrial planets were formed.

Phosphates and feldspar are secondary minerals that form in response to thermal metamorphism of ordinary chondrites. These minerals can be used as tools for understanding the composition of fluids that are present during their formation and evolution. Specifically, the $\mathrm{X}$ anion site in apatite records information about the relative abundance of the halogens $\mathrm{Cl}$ and $\mathrm{F}$ in addition to $\mathrm{OH}$, an indicator of the presence of water. Feldspar contains information about the relative abundance of the alkali elements $\mathrm{Na}$ and $\mathrm{K}$, which are readily transported in aqueous fluids, and can contain microtextures that indicate the presence of aqueous fluids.

In the discussion below, we compare our study on phosphates and feldspar in L chondrites to previous studies on these minerals in $\mathrm{H}$ and LL chondrites (Kovach and Jones 2010; Jones and McCubbin 2012; Jones et al. 2014). We examine the similarities and differences in secondary mineralogy between the three ordinary chondrite groups to further understand the metamorphic history of each group. We compare the phosphate mineralogy of brecciated and non-brecciated chondrites which gives insight into the mineralogical effects imparted by impact processing. We discuss the overall mechanisms and timing for the formation of secondary minerals and the evidence for the presence of fluids during metamorphism. Finally, we use apatite to estimate the bulk halogen abundances in ordinary chondrites and compare these to measured bulk values from the literature as a means to assess uncertainties on halogen abundances. 


\section{Comparison of Secondary Phosphates and Feldspar in H, L, and LL Ordinary Chondrites}

Since phosphate and feldspar are both secondary phases, chemical and textural changes in these minerals through the metamorphic sequence inform us about the process and conditions of equilibration. A comparison of the different OC groups provides insight into the processes common to all three OC parent bodies as well as the individual characteristics of each parent body.

\section{Phosphates}

There are many similarities in phosphate mineralogy between the $\mathrm{L}$ chondrites described above and the H and LL chondrites described by Jones and McCubbin (2012) and Jones et al. (2014). We can make the following generalizations, although the observations have been made on a limited number of chondrites (3 LL chondrites, $3 \mathrm{~L}$ chondrites, $4 \mathrm{H}$ chondrites). Phosphates in all three ordinary chondrite groups show a small increase in phosphate abundance with increasing petrologic type, particularly between type 4 ( $0.4 \%$ volume) and types $5,6(0.5 \%$ volume $)$, when averaged across phosphate abundances of individual $\mathrm{H}, \mathrm{L}$ and LL chondrites. Although this increase is close to the error of $0.1 \%$ volume, it is consistent across all OC groups and appears to be meaningful. Maximum grain sizes range between $100 \mu \mathrm{m}$ and $400 \mu \mathrm{m}$ for both apatite and merrillite, and merrillite is typically larger than apatite. Maximum grain sizes in L and LL chondrites generally increase with increasing petrologic type, but $\mathrm{H}$ chondrite phosphates are more uniform in maximum grain size across all petrologic types. Overall, phosphate minerals in all three OC groups appear to have developed under similar conditions.

Because $\mathrm{P}$ is originally hosted in metal in unequilibrated chondrites (e.g. Zanda et al. 1994), we might expect to observe an increase in abundance of phosphate minerals, consistent with increasing metal content from LL to L to $\mathrm{H}$ chondrites. However, phosphate abundance does not appear to show any correlation with metal content: our mean total phosphate abundances ( $\%$ volume) in the different groups are 0.47 for $\mathrm{H}, 0.54$ for $\mathrm{L}, 0.46$ for LL. In fact, this observation is consistent with bulk chondrite $\mathrm{P}$ abundances: while bulk chondrites show a 540\% increase in metal content from LL to H chondrites (2.5 wt $\%$ to 16 wt $\%$ : Lodders and Fegley 1998), the corresponding bulk P contents show a much smaller increase of 32\% (910 ppm to $1200 \mathrm{ppm}$ : Lodders and Fegley 1998). This relatively small difference in bulk $\mathrm{P}$ abundances between the different OC groups means that in our studies it is likely that any systematic differences between the groups are below the precision of our abundance calculation method. The lack of correlation between phosphate (or bulk P) abundance and metal abundance is probably attributable to the fact that chondrule mesostasis is also an important source of $\mathrm{P}$ for formation of phosphates in ordinary chondrites (Jones et al. 2014).

The petrological occurrences of phosphate minerals are also similar among the three OC groups. Individual grains of apatite and merrillite occur throughout the chondrite matrix of all studied unbrecciated $\mathrm{H}$ and L (Fig. 1a-c) chondrites as well as types 5 and 6 LL chondrites. Individual grains of apatite are rare in the L/LL4 Bjurböle and absent from the LL3.9 Bo Xian, but apatite is commonly present in association with merrillite in both chondrites. Apatite/merrillite intergrowth and reaction textures were reported for LL3.9, L/LL4, LL6, H4, and H5 chondrites but we did not observe similar textures in the unbrecciated L chondrites, with the exception of a single intergrowth grain in the L4 Santa Barbara (Fig. 2b). Jones et al. (2014) argued that these textures are the result of incomplete coupled dissolution-reprecipitation reactions, which suggests that in low petrologic type L chondrites, any similar reactions that may have occurred have gone to completion. This would indicate that halogen-bearing fluids were more common in low petrologic type L chondrites than in H or LL. In general, apatite/merrillite reactions are less common in higher petrologic types. In an onion shell model, the higher petrologic type OCs are sourced deeper, and thus may have been exposed to a larger volume of halogenbearing fluid, as well as being at a higher temperature, allowing for the replacement reaction to go to completion.

In all three groups, apatite and merrillite typically have no preferred silicate association but they are commonly associated with Fe,Ni metals, sulfides, and chromite (Fig. 2c, 3a-c,e-f) and are found adjacent to voids (Fig. 2c-e, 3a,f). Both minerals occasionally contain silicate inclusions, typically olivine and feldspar but rarely pyroxene (Fig. 2e-f, 3a,c-d). In LL3.9 and L/LL4 chondrites, merrillite is observed 
as small, rounded inclusions in $\mathrm{Fe}, \mathrm{Ni}$ metal grains but such inclusions were not observed in unbrecciated type $4 \mathrm{~L}$ or $\mathrm{H}$ chondrites. Since these inclusions most likely migrate out of the metal during textural equilibration in higher petrologic types (5 and 6), our interpretation of their absence in type $4 \mathrm{~L}$ and $\mathrm{H}$ chondrites is that the type 4 chondrites we studied experienced higher temperatures than the LL3.9 and L/LL4 chondrites from Jones et al. (2014).

In the L6 chondrite, Bruderheim we observed merrillite in association with some chromiteplagioclase assemblages (Fig. 3f). There is a similar association of apatite and merrillite with chromiteplagioclase assemblages in the LL6 Saint Séverin (Jones et al. 2014). Chromite-plagioclase assemblages are thought to be indicators of shock (Rubin 2003) and their presence is consistent with the moderately high shock stage assigned to Bruderheim (S4; Stöffler et al. 1991) and the complex shock history of Saint Séverin (Ashworth et al. 1977; Ashworth 1980; Leroux et al. 1996). Jones et al. (2014) proposed that since phosphates are readily incorporated into partial chondritic melts (Feldstein et al. 2001), impactgenerated melts include a phosphate component which then crystallized back out of the melt as an igneous mineral. In the example in Bruderheim, there is no apparent compositional difference between merrillite associated with the chromite-plagioclase assemblage and other merrillite in the rock: hence, equilibration of the whole rock likely occurred after formation of the chromite-plagioclase assemblage. However, if shock does play a role in phosphate formation, $\mathrm{Pb}-\mathrm{Pb}$ ages based on apatite may not only record metamorphism, but also post-metamorphic shock events (Jones et al. 2014). The fracturing noted in the phosphates, particularly in apatite (Fig. 2a-d), may also be due to the effects of shock.

Alternatively, fractures could be related to initial growth of the phosphate grains as fine-grained aggregates. The aggregates then experienced textural equilibration during thermal metamorphism because there is a decrease in the abundance of fractures with increasing petrologic type.

In all three OC groups, apatite compositions are similar in that they are all Cl-rich and all show a similar degree of compositional heterogeneity. However, each group has a distinct field on the apatite anion ternary. Figure 9 compares apatite anion compositions between the three ordinary chondrite groups: points represent single analyses and fields enclose all analyses reported for all samples within the group. In general, there is a trend of increasing "other" component $(0.05,0.09$, and 0.17 mean atom $\%$ anion) from $\mathrm{H}$ to $\mathrm{L}$ to LL chondrites, although $\mathrm{L}$ chondrite apatites overlap considerably with both $\mathrm{H}$ and LL fields. Figure 10 shows relative halogen compositions plotted as $\mathrm{Cl} /(\mathrm{Cl}+\mathrm{F}) \times 100$ (hereafter $\mathrm{Cl} \#$ ) for each chondrite, with error bars representing $1 \sigma$ and group averages signified by red vertical lines. Average apatite compositions for $\mathrm{H}$ and $\mathrm{L}$ chondrites are similar $(\mathrm{Cl} \#=84.9$ and 84.7 , atomic $\mathrm{Cl} / \mathrm{F}=6.5$ and 5.9 respectively) although there is much more scatter for individual chondrites in the $\mathrm{H}$ group compared with the $\mathrm{L}$ chondrites. $\mathrm{LL}$ chondrites are more $\mathrm{F}$ rich with average $\mathrm{Cl} \#=76.1$ and atomic $\mathrm{Cl} / \mathrm{F}=3.2$. The single $\mathrm{L} / \mathrm{LL}$ chondrite Bjurböle has an average apatite composition $(\mathrm{Cl} \#=83.9$, atomic $\mathrm{Cl} / \mathrm{F}=5.6)$ closer to $\mathrm{L}$ and $\mathrm{H}$ chondrites than LL chondrites.

Slight differences in $\mathrm{Cl} / \mathrm{F}$ ratios among individual meteorites within each chondrite group appear to reflect differences in fluid chemistry. These differences are independent of petrologic type in $\mathrm{H}$ and LL chondrites but $\mathrm{L}$ chondrites do show a slight trend towards decreasing atomic $\mathrm{Cl} / \mathrm{F}$ with increasing petrologic type. It is not apparent whether the $\mathrm{L}$ trend is process-related or purely coincidental. Given that $\mathrm{F}$ is more volatile than $\mathrm{Cl}$, and if $\mathrm{Cl} / \mathrm{F}$ ratios are controlled by temperature, we would expect a trend toward more $\mathrm{Cl}$-rich compositions with increasing degree of metamorphism and not the observed trend toward more F-rich compositions. In addition, because the $\mathrm{L}$ trend is not reproduced in the $\mathrm{H}$ or LL chondrites, it is more likely that differences in fluid chemistry between the petrologic types are due to the local environments rather than metamorphic history. Overall, the similarity in apatite compositions between the three groups implies the same process is forming apatite on all three parent bodies, but with minor differences in the fluid chemistry that controls apatite composition, as discussed in more detail below.

Merrillite compositions are also similar among the three OC groups. Figure 6 shows histograms of merrillite Mg\# for $\mathrm{H}$ (Jones and McCubbin 2012), L (this work), and LL (Jones et al. 2014) chondrites as well as the brecciated chondrite, Kendleton. All merrillite is Mg-rich with mean Mg\# between 86 and 94 for all groups and petrologic types. H chondrites have a slightly higher average Mg\# (93) than L (90) 
and LL (91) chondrites which is consistent with the more reduced nature, and higher Mg\# in olivine and pyroxene, for $\mathrm{H}$ chondrites. The average $\mathrm{Mg \#}$ for merrillite is higher than the average $\mathrm{Mg \#}$ for olivine and low-Ca pyroxene (olivine Mg\#: 82, 76, 71 for H, L, LL; low-Ca pyroxene Mg\#: 84, 80, 76 for H, L, LL; Brearley and Jones 1998).

Within the L and LL chondrites, merrillite Mg\# is lower in type 4 than in types 5 and 6 (Fig. 6). In addition, the $\mathrm{L}$ chondrites show an increase in degree of compositional equilibration with increasing petrologic type (Fig. 6), a trend that is possibly present but not as clear in the data for LL chondrites. In contrast, $\mathrm{H}$ chondrite merrillite has approximately the same $\mathrm{Mg \#} \mathrm{through} \mathrm{the} \mathrm{petrologic} \mathrm{sequence} \mathrm{and} \mathrm{no}$ trend of increasing compositional equilibration with petrologic type. The differences in merrillite equilibration between the $H$ chondrites and L and LL chondrites are also reflected in the feldspar equilibration history, as discussed below.

\section{Feldspar}

Feldspar within chondrules in $\mathrm{L}$ chondrites shows textural and compositional changes with increasing petrologic type that we interpret as progressive equilibration in response to metamorphism. Average grain size increases from types 4 to 6 . Fine-grained oxide inclusions and micropores are common in anorthitic and albitic plagioclase in type 4, rare in type 5, and absent in type 6. Albite replaces anorthite along grain boundaries in petrologic type 4. Fine-scale K-feldspar exsolution from albitic plagioclase is present in types 4 and 5 but absent in type 6. There is a wide range of plagioclase compositions, An ${ }_{88^{-}}$ $\mathrm{An}_{2}$, in the L4 chondrites Santa Barbara and Kramer Creek and we measured K content up to Or 23 in Santa Barbara. Plagioclase compositions are considerably more restricted in the L5 chondrites Elenovka and Roy 1933 with a maximum range of $\mathrm{An}_{17}-\mathrm{An}_{4}$ but $\mathrm{K}$ contents range up to Or 65 for coarse $\mathrm{K}$-feldspar regions in Roy 1933. Type 6 Bruderheim is fully equilibrated with a plagioclase composition of $\mathrm{An}_{10}$ and a K-feldspar content of $\mathrm{Or}_{6}$.

Characteristics of feldspar in types 4-6 L chondrites described above are very similar to feldspar within chondrules of type 4-6 LL chondrites reported by Kovach and Jones (2010). In the LLs, grain sizes increase from types 4 to 6 and albitic rims around anorthite cores are present in type 4 but absent in types 5 and 6. The fine-grained oxides (Fig. 7b) and micropores (Fig. 7b,d,f) we observe in L chondrite feldspar were not reported in the LL chondrites. However, the Kovach and Jones (2010) study focused on clear areas of plagioclase, and areas with complex microtextures were avoided. K-feldspar exsolution from albite was only reported for type 5 LL chondrites. Type 6 LL chondrites contain largely uniform regions of albitic plagioclase.

Feldspar compositions in L and LL chondrites are also similar: LL chondrites show compositional progressive equilibration with increasing petrologic type, from a wide range in L/LL4 Bjurböle $\left(\mathrm{An}_{85}\right.$ to $\left.\mathrm{An}_{5}\right)$, to a much more restricted range in LL5 and LL6 ( $\left.\sim \mathrm{An}_{10}\right)$ (Kovach and Jones 2010). The LL6 Saint Séverin has a slightly larger compositional variation in An and Or than the L6 Bruderheim. Kovach and Jones (2010) proposed that the relative heterogeneity of feldspar compositions in Saint Séverin compared to other type 6 chondrites was due to elemental redistribution during pre- and sin-metamorphic shock (Ashworth et al. 1977; Ashworth 1980; Leroux et al. 1996) and incomplete annealing during metamorphism (Rubin 2004).

In contrast to $\mathrm{L}$ and LL chondrites, feldspar in petrologic type 4-6 $\mathrm{H}$ chondrites has a single albitic plagioclase composition, $\sim \mathrm{An}_{12} \mathrm{Or}_{6}$ (Kovach and Jones 2010) although Rubin (1992) showed that variable plagioclase compositions ( $u$ p to $\mathrm{An}_{28}$ ) can occur in equilibrated $\mathrm{H}$ chondrites due to the effects of shock. Grain size does increase with increasing petrologic type in the $\mathrm{H}$ chondrites but anorthitic plagioclase was not observed by Kovach and Jones (2010). K-feldspar exsolution also was not observed by Kovach and Jones (2010), but we have since shown that it is present (Lewis et al. 2016). Since the difference between petrologic types 3 and 4 is based on the degree of olivine equilibration, we would assume that type 4 chondrites from the three groups reached similar peak temperatures for similar durations. Hence, there must be a factor other than peak temperature that controls the differences in feldspar properties between $\mathrm{H}$ chondrites and L, LL chondrites. Below we discuss the possibility that the 
differences are caused by a difference in timing of fluid activity, fluid composition, and/or fluid abundances during the early stages of metamorphism.

\section{Phosphates in Regolith Breccias}

In contrast to unbrecciated chondrites of all ordinary chondrite groups, the regolith breccia Kendleton has a heterogeneous, lithology-dependent distribution of apatite compositions (Fig. 5b, 10, Table 3). The L3 and L5 clasts have apatite compositions similar to each other $(\mathrm{Cl} \#=83.9$ and 82.0, atomic $\mathrm{Cl} / \mathrm{F}=4.7$ and 4.5 , respectively $)$ and similar to those of the unbrecciated L chondrites $(\mathrm{Cl} \#=84.7$, $\mathrm{Cl} / \mathrm{F}=5.9)$, but apatite in the $\mathrm{L} 4$ host material is significantly more $\mathrm{F}$-rich $(\mathrm{Cl} \#=64.8, \mathrm{Cl} / \mathrm{F}=1.9$, Fig. 10). In contrast, merrillite compositions in Kendleton are fairly homogeneous and show no significant differences among the three lithologies: they are similar to unbrecciated L chondrites (Fig. 6).

Texturally, the Kendleton L3 clast contains small, round merrillite inclusions within Fe,Ni metal, similar to LL3.9 and L/LL4 chondrites (Jones et al. 2014). The L3 clast has a lower phosphate abundance than the other $\mathrm{L}$ chondrites but this measurement may not be very accurate due to the small size of the clast (Fig. 1d, Table 2). The L4 host material contains roughly the same phosphate abundance as the unbrecciated L4 Santa Barbara, but it has a high proportion of merrillite (97\%) compared to approximately equal amounts of apatite and merrillite in Santa Barbara (Fig. 1e, Table 2). The L5 clast contains roughly equivalent abundances and proportions of phosphates to the unbrecciated L5 Elenovka (Table 2). Apatite-merrillite intergrowth textures are common in Kendleton's L4 host (Fig. 4c) and L5 clast (Fig. 4e-f) but we did not observe these textures in unbrecciated type 4 and 5 L chondrites with the exception of the single grain in Santa Barbara (Fig. 2b). However, these intergrowth textures are present in LL3.9, L/LL4, LL6, H4, and H5 chondrites studied by Jones et al. (2014) and Jones and McCubbin (2012).

A difference in apatite compositions between lithologies is also observed in the $\mathrm{H}$ regolith breccia, Zag (Jones et al. 2011). Apatite in the type 4 lithology and one type 6 clast of Zag have Cl-rich compositions similar to unbrecciated $\mathrm{H}$ chondrites, but apatite in a second type 6 lithology is considerably more variable and extends from $\mathrm{Cl}$-rich to F-rich compositions.

Based on the observations from these two meteorites, it appears that relatively F-rich apatite might be a common feature of surficial material on ordinary chondritic asteroids. There are several possible explanations for how this could occur. For Kendleton, we need a mechanism that results in lower abundance of apatite relative to merrillite in the L4 lithology, along with a more F-rich apatite composition. Since apatite in all the unbrecciated chondrites is $\mathrm{Cl}$-rich, we assume that we need a process that results in F enrichment in the L4 lithology, rather than F depletion in the other material. F could have been introduced during impact processing on the asteroid surface. Impact melt veins are common in Kendleton (e.g. Fig. 1d) and the release of volatiles, including the particularly volatile F, through the regolith from impact melt veins and pools could have reacted with existing Cl-rich apatite in order to produce the more F-rich compositions we observe.

It is also possible that fluorine could have an exogenous origin, from a volatile-rich impactor. For Zag and the H5 breccia Monahans, evidence for an external volatile source comes from halite and sylvite that have been shown to be of non-OC origin (Yurimoto et al. 2010). The presence of carbonaceous chondrite material within Zag is also consistent with a volatile-rich impactor (Zolensky et al. 2003). However, the source of the $\mathrm{F}$ in such a volatile-rich impactor is difficult to ascertain. For a carbonaceous impactor, the host phase for $\mathrm{F}$ in carbonaceous chondrites is not known (Brearley and Jones 2016). It is possible that $\mathrm{F}$ could be contained within amorphous phases in the matrix that would easily be released into the surrounding material, even with mild impact-induced heating.

The small phosphate grain sizes and low abundance of apatite in the Kendleton L4 lithology may also be related to impact processing. An impact could have disrupted the L4 material during metamorphism, after merrillite formed but before fluids could alter a significant amount of the merrillite to apatite (e.g. Fig. 4c). The impact could have fragmented the phosphates into small grains (Fig. 1e) and imparted the F-bearing component recorded in the apatite, while possibly forming additional apatite in the vein-filling morphology (Fig. 4d). 
If F-rich apatite is related to an impact process, we need to consider why this only affected certain lithologies. One possibility is that the affected lithologies were substantially more permeable during F infiltration (e.g. unconsolidated regolith) and thus preferentially altered over the less permeable lithologies. However, this model does not seem likely because there is no evidence for more F-rich apatite at the clast edges as we would expect for a single impact event releasing $\mathrm{F}$ through the material. A more plausible model is that the F-rich lithology was close to the source of F, e.g. at the surface of the asteroid, and that the unaltered lithologies were incorporated later during excavation by subsequent impact events. This would be consistent with a rubble-pile model for the parent asteroid. The mixed shock stages of the three lithologies may be further evidence of multiple impact events. Mixed shock stages within a regolith breccia are not uncommon (Rubin 2004) though it is possible that the lower shock stage reported for the Kendleton L5 could be attributed to post-shock annealing. It is also possible that some of the apatite crystallized from an F-rich impact melt. However, apatite textures in the L4 host (Fig. 4c,d) are more consistent with alteration by fluids, i.e. they show replacement and vein-filling textures. Clearly regolith breccias have experienced complex chemical processing in addition to mechanical processing.

\section{Formation and Evolution of Secondary Minerals: Mechanisms, Timing, and the Role of Fluids}

Metamorphism in ordinary chondrites has long been considered to be a solid-state process whereby progressive textural and compositional equilibration occur in a closed system as a response to increasing temperature (Huss et al. 2006). There is general agreement that the source of heating was the decay of short-lived radioisotopes during the first few million years of the solar system, shortly after the asteroids accreted (McSween et al. 2002). Heating may also have resulted from impacts (Rubin 2004). However, as previously discussed, there are only rough constraints on the overall metamorphic environment: peak temperatures are poorly constrained and the role of metasomatic fluids, which may represent an open system, is not understood. We can address some of these unknowns by considering the metamorphic environments from which secondary minerals form in the three ordinary chondrite groups.

The general model for formation of phosphate minerals and feldspar is that merrillite forms from the reaction of metal-derived $\mathrm{P}$ with olivine, pyroxene, chondrule mesostasis, and matrix material (Ahrens 1970; Jones et al. 2014), apatite forms from reactions and further equilibration within this mineral assemblage, and fine-grained albitic plagioclase crystallizes out of chondrule mesostasis (Van Schmus and Wood 1967). All mineral grains coarsen and experience progressive chemical and textural equilibration with increasing extent of thermal processing. We compare our observations of phosphate and feldspar development through the petrologic sequence to the general model of thermal metamorphism, in order to interpret the mechanisms and relative timing of their formation, and discuss the evidence from each of these minerals for the presence, composition, and timing of fluids during the metamorphic process.

Jones et al. (2014) trace the chemical origin of phosphate minerals in LL chondrites in detail and propose both solid-state and fluid-based formation mechanisms. They suggest that in lower petrologic types ( $\leq$ type 4 ), merrillite forms via a solid-state reaction with oxidized $\mathrm{P}$ (from Fe,Ni metal), and finegrained apatite-merrillite assemblages form via fluid reactions with merrillite and/or silicate minerals. Rubin and Grossman (1985) reported chlorapatite rims around several Fe,Ni metal grains in the LL3.2 Krymka, which indicates the phosphate formation process occurs early in the metamorphic process. In higher petrologic types (types 5 and 6), apatite can form either via an interface-coupled dissolutionreprecipitation reaction between existent merrillite and a halogen-bearing fluid, or by direct precipitation from a fluid. Thermal metamorphism also accounts for the general increase in grain size with increasing petrologic type.

The lack of compositional equilibration in apatite that would be expected for a metamorphic origin is explained by Jones et al. (2014) as overprinting by a late-stage reaction with dry, Cl-rich fluids. Each chondrite has its own individual mean apatite composition so that fluid compositions appear to be fairly localized within a single parent body. Similarly, the heterogeneity within each chondrite group indicates a low fluid-rock ratio. Since phosphate minerals share similar properties in the H, L, and LL groups, as discussed above, we consider the processes governing phosphate formation to be similar 
between the three ordinary chondrite groups so that the mechanisms described above for LL chondrites are also valid for $\mathrm{H}$ and $\mathrm{L}$ chondrites.

At first glance, the initial formation of feldspar from chondrule mesostasis is a more straightforward process. Chondrule mesostasis is typically feldspathic in composition (Scott and Krot 2014) so thermal metamorphism should lead to the crystallization of mesostasis into feldspar. This view is supported by the fact that there is a wide range of plagioclase compositions $\left(\sim \mathrm{An}_{85}-\mathrm{An}_{5}\right)$ in the chondrules of type 4 L (this study) and LL (Kovach and Jones 2010) chondrites and each chondrule has an average plagioclase composition that is distinct and likely related to the original composition of the mesostasis. The diversity in plagioclase compositions shows that crystallization of mesostasis must have occurred before diffusional equilibration across the chondrite could have taken place. In addition, primary igneous plagioclase present within the chondrule mesostasis, such as that identified in the LL3.0 Semarkona (Lewis and Jones 2015), may aid the nucleation of secondary plagioclase during the crystallization process.

Equilibration of plagioclase to albitic compositions with increasing petrologic type in $\mathrm{L}$ and LL chondrites is not only a solid state process. We propose that chemical equilibration of feldspar is a metasomatic process involving a hydrous, alkali-bearing fluid. In types 4 and 5, anorthitic plagioclase shows a range of alteration features indicative of the action of water, including the replacement by albite (albitization) along grain boundaries and the presence of micropores. Albitization is an interface-coupled dissolution-reprecipitation reaction that is common in terrestrial water-rock interactions with alkalibearing fluids (Putnis 2009). Development of porosity indicates the dissolution of anorthitic plagioclase by an aqueous fluid and is commonly associated with the albitization reaction (Engvik et al. 2008; Hövelmann et al. 2010).

Hövelmann et al. (2010) conducted albitization experiments on crystals of labradorite $\left(\mathrm{An}_{60}\right)$ and oligoclase $\left(\mathrm{An}_{23}\right)$ and showed that the reaction is very rapid. They were able to produce albitic rims on the plagioclase grain up to $50 \mu \mathrm{m}$ across in less than two weeks in a sodium silicate solution at $600^{\circ} \mathrm{C}$ and 2 kbars. At the experimental conditions the fluid had a $\mathrm{pH}$ of 9 and enough was added to theoretically convert all the plagioclase to albite. Grains of anorthitic plagioclase in type $4 \mathrm{~L}$ and LL chondrites are typically much smaller than $50 \mu \mathrm{m}$ but have rims only $\sim 1-3 \mu \mathrm{m}$ in width (e.g. Fig. $7 \mathrm{~b}$ ) indicating that the albitization reaction did not go to completion. However, the predominantly albitic composition of petrologic types 5-6 L and LL and types 4-6 $\mathrm{H}$ chondrites show that the reaction has gone to completion under these metamorphic conditions. There could be a number of reasons for the differences in the extent of these reactions, including variability in temperature, pressure, composition, duration, and/or the availability of the metasomatizing fluids (i.e. water-rock ratio).

The most obvious difference between the petrologic types is temperature. The peak temperature range attributed to type $4-5$ chondrites $\left(500-800^{\circ} \mathrm{C}\right)$ encompasses the temperature at which the experiments of Hövelmann et al. (2010) were conducted, $600^{\circ} \mathrm{C}$. Because there is not a well-defined division between peak temperatures in types 4 and 5, it is impractical to ascribe specific temperature dependent effects to these two types. However, even if type $4 \mathrm{~L}$ and LL chondrites only saw the lower end of that temperature range during metasomatism, we would expect more extensive albitization if all other conditions were equivalent to the above experimental setup (high pressure, $\mathrm{pH}$, and water-rock ratio). Types 6 OCs have seen temperatures above $800^{\circ} \mathrm{C}$ which would presumably cause the reaction to proceed faster and thus to completion.

Unlike temperature, pressure seems unlikely to have a significant effect in determining differences between petrologic types and OC groups. In the onion shell model, type 6 material should experience slightly higher pressures than type 4 material though the differences are not likely to be significant. The interior pressure of chondritic asteroids is much lower (10s-100s of bars) than the experimental pressure (2 kbars) used by Hövelmann et al. (2010). However, pressure could have an important effect on fluid composition relative to the experimental study. Converting anorthite to albite depends on the availability of $\mathrm{Na}$ and $\mathrm{Si}$ in solution. While $\mathrm{Na}$ is highly soluble, limits in Si solubility may restrict the rate at which the reaction will proceed. Si solubility increases with increasing temperature, pressure, and pH (Alexander et al. 1954; Morey et al. 1964; Fournier and Rowe 1977). At 
high temperature and $\mathrm{pH}$, silica solubility is very sensitive to pressure so the low pressure asteroidal environment may cause the rate of the albitization reaction to be limited by the amount of Si available in solution (Fournier and Rowe 1977). Similarly, silica solubility may be controlled by $\mathrm{pH}$ and/or temperature effects. Overall, the differences in silica solubility between the asteroidal environment and experimental conditions may significantly reduce the rate at which chondritic albitization occurred.

Fluid availability and the duration of fluid-bearing episodes also control the degree of albitization. Lower amounts of fluid (i.e. low water-rock ratio) in type 4 and $5 \mathrm{~L}$ and LL chondrites could cause lower degrees of albitization whereas higher amount of fluid in $\mathrm{H}$ chondrites and type $6 \mathrm{~L}$ and LL chondrites would allow the reaction to proceed to completion. Alternatively, a similar effect could be produced by a limited duration of fluid activity coupled with a low reaction rate due to low silica solubility. If one assumes the same amount of fluid was present in ordinary chondrites of all petrologic types (e.g. derived locally from ices incorporated into the matrix), an onion-shell asteroid would experience longer durations of metasomatism (and at higher temperatures) with increasing petrologic type. Given a slow rate of albitization, only the longest duration of metasomatism (type 6) would result in a complete replacement of anorthitic plagioclase. However, this does not address the difference between type $4 \mathrm{H}$ chondrites and $\mathrm{L}$, LL chondrites for which another factor, such as fluid composition, must be invoked.

In addition to $\mathrm{Na}$, increased $\mathrm{K}$ content within albitized regions in type 4 and 5 chondrites implies the metasomatizing fluid is also $\mathrm{K}$-bearing. $\mathrm{K}$ was clearly incorporated into the feldspar during the metamorphic processes and exsolved as K-feldspar during cooling (e.g. Figs. 7d,h,j). Both Na and K are incorporated into the feldspar structure at a high temperature where the solvus covers a small compositional range. As the temperature decreases, the solvus widens and the two feldspars unmix to produce cryptoantiperthite (Jones and Brearley 2011; Lewis et al. 2016). Replacement reactions such as this are common in alkali feldspars in hydrothermal systems on Earth (Parsons and Lee 2009). The presence of K-feldspar exsolution near voids (Fig. 7h) shows that fluids flow through the chondrules using inherent porosity. However, the amount of $\mathrm{K}$ present within the fluid appears to be limited because $\mathrm{K}$ content in the plagioclase (as seen by K-feldspar exsolution) is not typically uniform from chondrule to chondrule or even within a single chondrule (Fig. 7h,j). We did not observe K-feldspar exsolution in type $6 \mathrm{~L}$ and $\mathrm{H}$ chondrites: this could be the result of lower $\mathrm{K}$ abundances in the fluid, although Or contents of albitic feldspar in type 6 chondrites are comparable to those in type 5. Orville (1963) showed that the $\mathrm{Na} / \mathrm{K}$ ratio of a fluid in equilibrium with alkali feldspar decreases with increasing temperature independent of feldspar composition. The higher temperature of type 6 OCs could increase K solubility in the fluid and decrease the amount of $\mathrm{K}$ incorporated into feldspar. The absence of exsolution could also indicate a more rapid cooling rate for the type 6 material, which would be inconsistent with an onion-shell model.

The above arguments assume that metasomatizing fluids were acting during peak metamorphism within each of the petrologic types. However, thermal modelling of an onion shell asteroid (e.g. Harrison and Grimm 2010) shows that peak temperatures for each petrologic type are not coincidental: there is a time interval of millions of years between the peak temperature of type 4 (earlier) and type 6 (later). An alternative model for feldspar formation is that the fluid causing the albitization reactions was derived from a deep source (not the local environment) and was delivered relatively late in the thermal evolution of the parent body, e.g. near peak metamorphism of type 6 . In this case, the lower petrologic types would have cooled down during retrograde metamorphism and the albitization reaction would proceed slower at these lower temperatures. Such a model could also explain the difference in equilibration between type 4 $\mathrm{H}$ (more albitized) and L, LL (less albitized) chondrites. An earlier release of metasomatizing fluids (e.g. near peak metamorphism of type 4 material) would allow the reaction to occur at a higher temperature, and proceed to completion, in types 4-6.

In order to fully understand the metasomatic/metamorphic environment, we must reconcile observations on phosphate and feldspar minerals. Our generalized model is as follows. First, plagioclase crystallizes from chondrule mesostasis during the onset of metamorphism at roughly the same time that merrillite forms from the oxidation of metal-derived phosphorous. These are thought to be solid-state processes although fluid assistance is not necessarily ruled out. Also, there may be some primary feldspar 
in chondrules. Alteration of Ca-bearing feldspar to albite, and alteration of merrillite to apatite, requires a hydrous brine to facilitate the interface-coupled dissolution-reprecipitation reactions. However, the increasing degree of albitization with increasing petrologic type is not reflected in a change in the apatite/merrillite ratio which actually decreases slightly with increasing petrologic type, owing largely to an increase in merrillite abundance. It appears that the conditions that allowed for the conversion of merrillite to apatite were limited in duration and predominantly occurred within lower petrologic types. In higher petrologic types, merrillite abundances continued to increase, consistent with the presence of an alkali-bearing fluid. During retrograde metamorphism, K-feldspar exsolved from the albite and a dry, Clrich fluid overprinted the apatite compositions but did not affect plagioclase compositions.

The composition of the fluid that alters anorthite to alkali feldspar and merrillite to apatite has been characterized above as a hydrous brine containing the alkali elements $\mathrm{Na}$ and $\mathrm{K}$ and the halogens $\mathrm{Cl}$ and F. The fluid also contains Si inferred by the alteration of anorthite to albite. We can show the feldspar alteration by the following simplified equation where anorthite and low-Ca pyroxene react with a siliceous brine to form alkali feldspar, Ca-pyroxene, oxides (spinel in this case), with release of $\mathrm{CaCl}_{2}$ back into the fluid:

$$
2 \mathrm{CaAl}_{2} \mathrm{Si}_{2} \mathrm{O}_{8}+\mathrm{Mg}_{2} \mathrm{Si}_{2} \mathrm{O}_{6}+2 \mathrm{SiO}_{2}(a q)+2 \mathrm{NaCl}(a q) \rightarrow 2 \mathrm{NaAlSi}_{3} \mathrm{O}_{8}+\mathrm{CaMgSi}_{2} \mathrm{O}_{6}+\mathrm{MgAl}_{2} \mathrm{O}_{4}+\mathrm{CaCl}_{2}(a q)
$$

While we do not see direct evidence for the consumption of low-Ca pyroxene, we do see areas of albitized anorthite with accessory oxides and Ca-pyroxene. However, it is likely that chondrule mesostasis, and not low-Ca pyroxene, provides the important cations for the replacement reaction to proceed. $\mathrm{K}$ can follow $\mathrm{Na}$ into the alkali feldspar. The resultant $\mathrm{CaCl}_{2}(a q)$ can react with merrillite to form apatite according to the following simplified equation:

$$
3 \mathrm{Ca}_{9} \mathrm{NaMg}\left(\mathrm{PO}_{4}\right)_{7}+8 \mathrm{CaCl}_{2}(a q) \rightarrow 7 \mathrm{Ca}_{5}\left(\mathrm{PO}_{4}\right)_{3} \mathrm{Cl}+3 \mathrm{NaCl}(a q)+3 \mathrm{MgCl}_{2}(a q)
$$

In this case, the resultant $\mathrm{NaCl}$ can feed back into the anorthite alteration reaction. $\mathrm{F}$ can follow $\mathrm{Cl}$ into apatite. However, the apatite reaction represented here does not take into account the late-stage, dry, Clrich fluid that may have overprinted the apatite composition. Apatite forming from a hydrous reaction should have a significant $\mathrm{OH}$ component in addition to the $\mathrm{Cl} / \mathrm{F}$ ratio of the fluid from which it formed.

Overall, evidence is mounting that fluids were present during thermal metamorphism and that a simple picture of solid-state recrystallization alone is not complete. The presence of fluids in equilibrated ordinary chondrites has been inferred previously from studies of modal mineralogy (McSween and Labotka 1993; Dunn, Cressey, et al. 2010; Dunn, McSween Jr., et al. 2010) and oxygen isotopes (Bridges et al. 1999; Li et al. 2000; Rubin 2005). McSween and Labotka (1993) suggested that the observed increase in $\mathrm{FeO}$ and decrease in Fe metal with progressive metamorphism could be caused by small amounts of water vapor. Similar observations were made by Dunn et al. (2010) using modal mineralogy determined by XRD. Rubin (2005) proposed that water could be derived from dehydration of phyllosilicates during metamorphism and could be responsible for the trend of decreasing $\delta^{17} \mathrm{O}$ and $\delta^{18} \mathrm{O}$ with increasing petrologic type observed by Clayton et al. (1991). Li et al. (2000) showed that plagioclase and glass separates from the LL3.9 chondrite Bo Xian had higher $\delta^{17} \mathrm{O}$ and $\delta^{18} \mathrm{O}$ than olivine and pyroxene and suggested this was due to interaction with ${ }^{16} \mathrm{O}$-poor hydrous fluid. Our studies of phosphates and feldspar show that interface-coupled dissolution-reprecipitation reactions in a hydrous halogen- and alkali-bearing fluid were at least partially responsible for changes in mineralogy, and the equilibration of plagioclase appears to be driven almost entirely by fluid processes. Late-stage anhydrous, Cl-rich fluids were proposed by Jones et al. (2014) to have overprinted apatite compositions during retrograde metamorphism.

\section{Cl and F Abundances in Ordinary Chondrites}

It is important to know bulk halogen abundances in chondrites because they are used to estimate the halogen compositions of the Earth and other terrestrial planets (McDonough and Sun 1995). However 
these values are not well constrained in chondrites (Brearley and Jones 2016) and elemental abundance compilations such as those compiled by Wasson and Kallemeyn (1988) and Lodders and Fegley (1998) provide widely varying values based on limited data. L chondrites have particularly large uncertainties with Wasson and Kallemeyn (1988) reporting $76 \mathrm{ppm}$ and $41 \mathrm{ppm}$ for bulk $\mathrm{Cl}$ and $\mathrm{F}$ respectively (atomic $\mathrm{Cl} / \mathrm{F}=1.0$ ) in contrast to $270 \mathrm{ppm}$ and $100 \mathrm{ppm}$ for $\mathrm{Cl}$ and $\mathrm{F}$ (atomic $\mathrm{Cl} / \mathrm{F}=1.4$ ) from Lodders and Fegley (1998). Brearley and Jones (2016) provide a review of the studies from which these compiled values were obtained and conclude that the halogen abundances of Wasson and Kallemeyn (1988) are likely more representative of the limited data but should still be treated with caution.

A number of halogen-bearing phases occur in unequilibrated ordinary chondrites, including sodalite, scapolite, and smectite in addition to apatite (Brearley and Jones 2016). Most of these phases are not stable at high temperatures and only apatite is present in chondrites which have undergone significant degrees of thermal metamorphism. Because of this, apatite is likely the major host of $\mathrm{Cl}$ and $\mathrm{F}$ in equilibrated (petrologic type 4-6) ordinary chondrites and we can use the abundances of $\mathrm{Cl}$ and $\mathrm{F}$ measured in apatite to understand the bulk halogen characteristics of ordinary chondrites. In Figure 9, we compare bulk Cl/F ratios for H, L, LL, and CI chondrites from Wasson and Kallemeyn (1988) with apatite compositions of the three ordinary chondrite groups. Apatite $\mathrm{Cl} / \mathrm{F}$ ratios in ordinary chondrites are significantly higher than bulk chondrite values of Wasson and Kallemeyn (1988). In fact, ordinary chondrite apatite actually shows $\mathrm{CI}-$ like $\mathrm{Cl} / \mathrm{F}$ ratios, with quite a lot of scatter, and the $\mathrm{Cl} / \mathrm{F}$ ratio in $\mathrm{L}$ chondrite apatite (atomic $\mathrm{Cl} / \mathrm{F}=5.9$ ) is very close to the $\mathrm{CI}$ ratio (atomic $\mathrm{Cl} / \mathrm{F}=5.7$ ). Figure 10 further illustrates this point by showing bulk $\mathrm{Cl} / \mathrm{F}$ ratios (expressed as $\mathrm{Cl} \#$ ) for ordinary and $\mathrm{CI}$ chondrites. The figure also illustrates differences between the compilations of Wasson and Kallemeyn (1988) and Lodders and Fegley (1998). There are two possible explanations for the differences between apatite and bulk chondrite $\mathrm{Cl} / \mathrm{F}$ ratios: either there are other F-bearing phases in equilibrated ordinary chondrites that have not been recognized, or the available bulk chondrite values are incorrect, with underestimated $\mathrm{Cl}$ and/or overestimated F abundances, as discussed by Jones et al. (2014).

We can obtain an independent estimate of bulk chondrite $\mathrm{Cl}$ and $\mathrm{F}$ abundances from our measurements of apatite abundances and compositions. For the $\mathrm{L}$ chondrites, apatite has average $\mathrm{Cl}$ and $\mathrm{F}$ abundances of $5.2 \mathrm{wt} \%$ and $0.5 \mathrm{wt} \%$ respectively (Table 3). Using the calculated average volume abundance of $0.17 \%$ for apatite (Table 2), the bulk $\mathrm{Cl}$ and $\mathrm{F}$ abundances due to the presence of apatite are roughly $91 \mathrm{ppm}$ and $9 \mathrm{ppm}$ respectively (not taking into account densities). These bulk values drop to 86 $\mathrm{ppm}$ and $8 \mathrm{ppm}$ for $\mathrm{Cl}$ and $\mathrm{F}$ respectively if the calculation includes the mineral density for chlorapatite (Bideaux et al. 2000) and the bulk density of L chondrites (Consolmagno et al. 2008). In comparison, the bulk L chondrite $\mathrm{Cl}$ abundance given by Wasson and Kallemeyn (1988) is very similar, $76 \mathrm{ppm}$. This is consistent with apatite being the major host for $\mathrm{Cl}$. However, the bulk value for $\mathrm{F}$ given by Wasson and Kallemeyn (1988) is 41 ppm, about 5 times greater than the F abundance accounted for by apatite alone. A similar discrepancy was shown for the LL chondrites (Jones et al. 2014) in that apatite is clearly the major carrier of $\mathrm{Cl}$, but $\mathrm{F}$ in apatite only accounts for $\sim 10 \%$ of the reported bulk value. Other workers have also reported discrepancies between apatite abundance and bulk F content (e.g. Reed 1964; Van Schmus and Ribbe 1969)

While bulk chlorine contents of the different chondrite groups are well established, reported bulk fluorine contents have large uncertainties (Brearley and Jones 2016). Although it is possible that F is present in other phases, as suggested by Reed (1964), it is unlikely that silicates would be able to retain significant $\mathrm{F}$ at the low pressures of OC parent bodies. We consider it more likely that reported halogen abundances of bulk ordinary chondrites have overestimated $\mathrm{F}$ abundances, and that the $\mathrm{CI}$-like $\mathrm{Cl} / \mathrm{F}$ ratio recorded in apatite is more representative of bulk OC values. If OCs have a CI-like $\mathrm{Cl} / \mathrm{F}$ ratio then perhaps all chondrites formed with a solar $\mathrm{Cl} / \mathrm{F}$ ratio that indicates a roughly uniform distribution of $\mathrm{Cl} / \mathrm{F}$ in early planetesimals.

\section{$\underline{\text { Summary \& Conclusions }}$}

We conducted a detailed study of phosphate and feldspar in equilibrated L ordinary chondrites in order to understand the metamorphic and metasomatic environment on the L parent body and compare it 
to previous studies of $\mathrm{H}$ and LL chondrites. Apatite abundances and compositions in L chondrites are Clrich and similar on average to $\mathrm{H}$ chondrites; both are similar to LL chondrites, but apatite in LL chondrites has a lower $\mathrm{Cl} / \mathrm{F}$ ratio. Merrillite abundances and compositions are similar among the three chondrite groups and show a trend of compositional equilibration with metamorphism. Feldspar in L chondrites shows an equilibration trend from a wide range of plagioclase compositions in petrologic type 4 to a homogeneous albitic composition in type 6 . This is very similar to the feldspar equilibration trend in LL chondrites, and different from $\mathrm{H}$ chondrites, in which plagioclase is homogeneous and albitic in petrologic types 4-6. Metasomatic fluids acted during metamorphic heating on the OC parent bodies. The fluids were alkali- and halogen-rich and likely hydrous during prograde metamorphism, transitioning to a more anhydrous, $\mathrm{Cl}$-rich composition after the asteroid began to cool. The differences in secondary minerals (largely plagioclase equilibration) between H and L, LL chondrites can be explained by differences in fluid abundance/duration or the timing of deep-sourced fluid release. Regolith breccias have lithology-dependent apatite compositions, some with more F-rich apatite compositions than unbrecciated chondrites, possibly due to F-rich degassing from impact melts or an F-rich impactor. Bulk $\mathrm{Cl} / \mathrm{F}$ ratios for ordinary chondrites inferred from apatite compositions are inconsistent with measured bulk chondrite halogen values. We suggest that this is because $\mathrm{F}$ abundances in bulk ordinary chondrites are overestimated, and that bulk $\mathrm{Cl} / \mathrm{F}$ ratios of ordinary chondrites are actually close to $\mathrm{CI}$ chondrite, i.e that they are unfractionated from solar values.

\section{Acknowledgements}

We would like to thank A. Rubin and M. Kimura for helpful reviews, Adrian Brearley and Francis McCubbin for useful conversations, and Mike Spilde for his help with the microprobe. We also thank Jane Gallegos who conducted analytical work on feldspar. Electron microprobe and SEM work was carried out in the Electron Microbeam Analysis Facility, Department of Earth and Planetary Sciences and Institute of Meteoritics, University of New Mexico. J. Lewis acknowledges support from the KelleySilver Foundation, University of New Mexico. The work was partially funded by NASA grant NNX12AH61G (P.I. R. Jones).

\section{References}

Ahrens L. H. 1970. The composition of stony meteorites (VIII) observations on fractionation between the L and H chondrites. Earth and Planetary Science Letters 9:345-347.

Alexander C. M. O., Barber D. J., and Hutchison R. 1989. The microstructure of Semarkona and Bishunpur. Geochimica et Cosmochimica Acta 53:3045-3057.

Alexander G. B., Heston W., and Iler R. K. 1954. The solubility of amorphous silica in water. The Journal of Physical Chemistry 58:453-455.

Ashworth J. R. 1980. Chondrite thermal histories: Clues from electron microscopy of orthopyroxene. Earth and Planetary Science Letters 46:167-177.

Ashworth J. R., Barber D. J., Brown G. M., and Smith J. V. 1977. Electron Microscopy of Some Stony Meteorites. Philosophical Transactions of the Royal Society of London A: Mathematical, Physical and Engineering Sciences 286:493-506.

Bideaux R. A., Bladh K. W., and Monte M. C. 2000. Handbook of Mineralogy: Arsenates, Phosphates, Vanadates, edited by Anthony J. W. Mineral Data Publishing. p. 111.

Brearley A. J. and Jones R. H. 1998. Chondritic meteorites. In Planetary Materials, edited by Papike J. J. Reviews in Mineralogy and Geochemistry, vol. 36. Chantilly, Virginia: The Mineralogical Society of America. pp. 3.1-3.398.

Brearley A. J. and Jones R. H. 2016. Halogens in chondritic meteorites. In Halogens, edited by Harlov D. Springer.

Bridges J. C., Franchi I. A., Sexton A. S., and Pillinger C. T. 1999. Mineralogical controls on the oxygen isotopic compositions of UOCs. Geochimica et Cosmochimica Acta 63:945-951.

Clayton R. N., Mayeda T. K., Goswami J. ., and Olsen E. J. 1991. Oxygen isotope studies of ordinary chondrites. Geochimica et Cosmochimica Acta 55:2317-2337. 
Consolmagno G. J., Britt D. T., and Macke R. J. 2008. The significance of meteorite density and porosity. Chemie der Erde 68:1-29.

Dunn T. L., Cressey G., McSween H. Y., and McCoy T. J. 2010. Analysis of ordinary chondrites using powder X-ray diffraction: 1. Modal mineral abundances. Meteoritics \& Planetary Science 45:123-134.

Dunn T. L., McSween Jr. H. Y., McCoy T. J., and Cressey G. 2010. Analysis of ordinary chondrites using powder X-ray diffraction: 2. Applications to ordinary chondrite parent-body processes. Meteoritics \& Planetary Science 45:135-156.

Ehlmann A. J., Scott E. R. D., Keil K., Mayeda T. K., Clayton R. N., Weber H. W., and Schultz L. 1988. Origin of fragmental and regolith meteorite breccias - Evidence from the Kendleton L chondrite breccia. In Lunar and Planetary Science Conference Proceedings, edited by Ryder G. pp. 545554.

Engvik A. K., Putnis A., Fitz Gerald J. D., and Austrheim H. 2008. Albitization of granitic rocks: The mechanism of replacement of oligoclase by albite. The Canadian Mineralogist 46:1401-1415.

Feldstein S. N., Jones R. H., and Papike J. J. 2001. Disequilibrium partial melting experiments on the Leedey L6 chondrite: Textural controls on melting processes. Meteoritics \& Planetary Science 36:1421-1441.

Fournier R. O. and Rowe J. J. 1977. Solubility of amorphous silica in water at high temperatures and high pressure. American Mineralogist 62:1052-1056.

Grossman J. N., Alexander C. M. O., Wang J., and Brearley A. J. 2000. Bleached chondrules: Evidence for widespread aqueous processes on the parent asteroids of ordinary chondrites. Meteoritics \& Planetary Science 35:467-486.

Harrison K. P. and Grimm R. E. 2010. Thermal constraints on the early history of the H-chondrite parent body reconsidered. Geochimica et Cosmochimica Acta 74:5410-5423.

Hövelmann J., Putnis A., Geisler T., Schmidt B., and Golla-Schindler U. 2010. The replacement of plagioclase feldspars by albite: observations from hydrothermal experiments. Contributions to Mineralogy and Petrology 159:43-59.

Huss G. R. 1979. The Matrix of Unequilibrated Ordinary Chondrites: Implications for the Origin and Subsequent History of Chondrites. Master's thesis, University of New Mexico, Albuquerque, New Mexico, USA.

Huss G. R., Rubin A. E., and Grossman J. N. 2006. Thermal metamorphism in chondrites. In Meteorites and the Early Solar System II, edited by Lauretta D. S., and McSween Jr. H. Y. Tucson, Az: The University of Arizona Press. pp. 567-586.

Jones R. H. and Brearley A. J. 2011. Exsolution in Feldspar in the Tuxtuac (LL5) Chondrite: A New Perspective on Cooling Rates for Metamorphosed Chondrites. (abstract \#5475) 74rd Annual Meeting of the Meteoritical Society.

Jones R. H. and McCubbin F. M. 2012. Phosphate Mineralogy and the Bulk Chlorine/Fluorine Ratio of Ordinary Chondrites. (abstract \#2029) 43rd Lunar and Planetary Science Conference.

Jones R. H., McCubbin F. M., Dreeland L., Guan Y., Burger P. V., and Shearer C. K. 2014. Phosphate minerals in LL chondrites: A record of the action of fluids during metamorphism on ordinary chondrite parent bodies. Geochimica et Cosmochimica Acta 132:120-140.

Jones R. H., McCubbin F. M., and Guan Y. 2011. Phosphate Mineralogy and the Role of Fluids in the Zag H Chondrite. (abstract \#2435) 42nd Lunar and Planetary Science Conference.

Kovach H. A. and Jones R. H. 2010. Feldspar in type 4-6 ordinary chondrites: Metamorphic processing on the H and LL chondrite parent bodies. Meteoritics \& Planetary Science 45:246-264.

Krot A. N., Zolensky M. E., Wasson J. T., Scott E. R. D., Keil K., and Ohsumi K. 1997. Carbidemagnetite assemblages in type-3 ordinary chondrites. Geochimica et Cosmochimica Acta 61:219237.

Leroux H., Doukhan J.-C., and Guyot F. 1996. An analytical electron microscopy (AEM) investigation of opaque inclusions in some type 6 ordinary chondrites. Meteoritics \& Planetary Science 31:767776. 
Lewis J. A. and Jones R. H. 2015. Primary Feldspar in Semarkona (LL3.00) Chondrules. (abstract \#2067) 46th Lunar and Planetary Science Conference.

Lewis J. A., Jones R. H., and Brearley A. J. 2016. Alkali Feldspar Exsolution in Ordinary Chondrites: Alkali Metasomatism, Metamorphism, and Cooling Rates. (abstract \#2559) 47th Lunar and Planetary Science Conference.

Li C., Bridges J. C., Hutchison R., Franchi I. A., Sexton A. S., Ouyang Z., and Pillinger C. T. 2000. Bo Xian (LL3.9): Oxygen-isotopic and mineralogical characterisation of separated chondrules. Meteoritics \& Planetary Science 35:561-568.

Lodders K. and Fegley B. 1998. The planetary scientist's companion, New York: Oxford University Press.

McCubbin F. M., Hauri E. H., Elardo S. M., Vander Kaaden K. E., Wang J., and Shearer C. K. 2012. Hydrous melting of the martian mantle produced both depleted and enriched shergottites. Geology.

McCubbin F. M., Steele A., Nekvasil H., Schnieders A., Rose T., Fries M., Carpenter P. K., and Jolliff B. L. 2010. Detection of structurally bound hydroxyl in fluorapatite from Apollo Mare basalt 15058,128 using TOF-SIMS. American Mineralogist 95:1141-1150.

McDonough W. F. and Sun S. -s. 1995. The composition of the Earth. Chemical Evolution of the Mantle 120:223-253.

McSween H. Y., Ghosh A., Grimm R. E., Wilson L., and Young E. D. 2002. Thermal evolution models of asteroids. In Asteroids III, edited by Bottke W. F., Cellino A., Paolicchi P., and Binzel R. P. Tucson, AZ: The University of Arizona Press. pp. 559-571.

McSween H. Y. and Labotka T. C. 1993. Oxidation during metamorphism of the ordinary chondrites. Geochimica et Cosmochimica Acta 57:1105-1114.

Morey G. W., Fournier R. O., and Rowe J. J. 1964. The solubility of amorphous silica at $25^{\circ}$ C. Journal of Geophysical Research 69:1995-2002.

Orville P. M. 1963. Alkali ion exchange between vapor and feldspar phases. American Journal of Science 261:201-237.

Parsons I. and Lee M. R. 2009. Mutual replacement reactions in alkali feldspars I: microtextures and mechanisms. Contributions to Mineralogy and Petrology 157:641-661.

Putnis A. 2009. Mineral replacement reactions. In Thermodynamics and Kinetics of Water-Rock Interaction. Reviews in Mineralogy and Geochemistry, vol. 70. Chantilly, Virginia: The Mineralogical Society of America. pp. 87-124.

Reed G. W. 1964. Fluorine in stone meteorites. Geochimica et Cosmochimica Acta 28:1729-1743.

Rubin A. E. 1992. A shock-metamorphic model for silicate darkening and compositionally variable plagioclase in CK and ordinary chondrites. Geochimica et Cosmochimica Acta 56:1705-1714.

Rubin A. E. 2003. Chromite-plagioclase assemblages as a new shock indicator; implications for the shock and thermal histories of ordinary chondrites. Geochimica et Cosmochimica Acta 67:2695-2709.

Rubin A. E. 2004. Postshock annealing and postannealing shock in equilibrated ordinary chondrites: implications for the thermal and shock histories of chondritic asteroids. Geochimica et Cosmochimica Acta 68:673-689.

Rubin A. E. 2005. Relationships among intrinsic properties of ordinary chondrites: Oxidation state, bulk chemistry, oxygen-isotopic composition, petrologic type, and chondrule size. Geochimica et Cosmochimica Acta 69:4907-4918.

Rubin A. E. and Grossman J. N. 1985. Phosphate-sulfide assemblages and Al/Ca ratios in type-3 chondrites. Meteoritics 20:479-489.

Scott E. R. D. and Krot A. N. 2014. 1.2 - Chondrites and Their Components. In Meteorites, comets and planets, edited by Davis A. M. Treatise on Geochemistry, vol. 1. Oxford: Elsevier-Pergamon. pp. 65-137.

Stöffler D., Keil K., and Edward R.D S. 1991. Shock metamorphism of ordinary chondrites. Geochimica et Cosmochimica Acta 55:3845-3867. 
Stormer J. C., Pierson M. L., and Tacker R. C. 1993. Variation of F and Cl X-ray intensity due to anisotropic diffusion in apatite during electron microprobe analysis. American Mineralogist 78:641-648.

Van Schmus W. R. and Ribbe P. H. 1969. Composition of phosphate minerals in ordinary chondrites. Geochimica et Cosmochimica Acta 33:637-640.

Van Schmus W. R. and Wood J. A. 1967. A chemical-petrologic classification for the chondritic meteorites. Geochimica et Cosmochimica Acta 31:747-765.

Wasson J. T. and Kallemeyn G. W. 1988. Compositions of Chondrites. Philosophical Transactions of the Royal Society of London A: Mathematical, Physical and Engineering Sciences 325:535-544.

Wlotzka F. 1993. A Weathering Scale for the Ordinary Chondrites. Meteoritics 28:460.

Yurimoto H., Itoh S., Zolensky M. E., Kusakabe M., and Karen A. 2010. Isotopic Compositions of Fluid Inclusions in Halites from Ordinary Chondrites. Meteoritics and Planetary Science Supplement 73:5178.

Zanda B., Bourot-Denise M., Perron C., and Hewins R. H. 1994. Origin and metamorphic redistribution of silicon, chromium, and phosphorus in the metal of chondrites. Science 265:1846-1849.

Zolensky M. E., Clayton R. N., Mayeda T., Chokai J., and Norton O. R. 2003. Carbonaceous Chondrite Clasts in the Halite-bearing H5 Chondrite Zag. Meteoritics and Planetary Science Supplement 38:5216. 
Table 1. Sample list.

\begin{tabular}{|c|c|c|c|c|}
\hline & Thin section & Petrologic type & Shock stage & Weathering \\
\hline Santa Barbara & UNM 120 & L4 & $\mathrm{S} 2$ & Fall \\
\hline Kramer Creek & UNM 82 & L4 & S2 & W3 \\
\hline Elenovka & UNM 246E & L5 & S3 & Fall \\
\hline Roy 1933 & UNM 31 & L5 & S3 & W2 \\
\hline Bruderheim & UNM 53 & L6 & S4 & Fall \\
\hline \multicolumn{2}{|c|}{ Kendleton, regolith breccia } & & & Fall \\
\hline L3 clast & UNM 710A & L3 & S3 & \\
\hline L4 host & UNM 713 & $\mathrm{~L} 4$ & S3 & \\
\hline L5 clast & UNM 714A & L5 & $\mathrm{S} 2$ & \\
\hline
\end{tabular}

Table 2. Phosphate abundances and grain sizes.

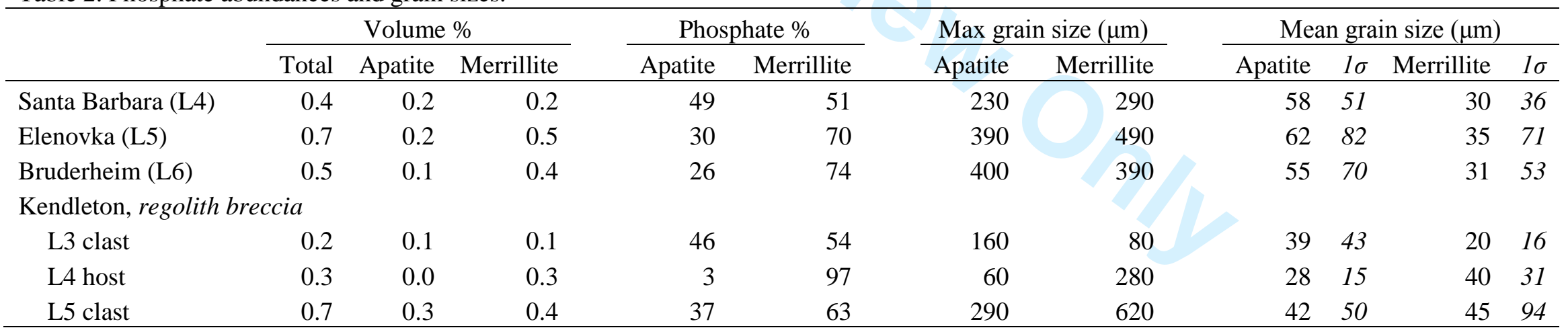


Table 3. Average apatite compositions

\begin{tabular}{|c|c|c|c|c|c|c|c|c|c|c|c|c|}
\hline & \multicolumn{2}{|c|}{ Santa Barbara } & \multicolumn{2}{|c|}{ Elenovka } & \multicolumn{2}{|c|}{ Bruderheim } & \multicolumn{6}{|c|}{ Kendleton } \\
\hline & L4 & $1 \sigma$ & L5 & $1 \sigma$ & L6 & $1 \sigma$ & L3 clast & $1 \sigma$ & L4 host & $1 \sigma$ & L5 clast & $1 \sigma$ \\
\hline $\mathrm{CaO}$ & 52.6 & 0.6 & 53.3 & 0.3 & 53.4 & 0.3 & 54.0 & 1.1 & 53.0 & 0.7 & 53.7 & 0.8 \\
\hline $\mathrm{MgO}$ & 0.05 & 0.06 & n.d. & & 0.04 & 0.02 & 0.04 & 0.02 & 0.18 & 0.16 & 0.02 & 0.02 \\
\hline $\mathrm{FeO}$ & 0.84 & 0.54 & 0.24 & 0.13 & 0.31 & 0.11 & 0.26 & 0.17 & 0.55 & 0.41 & 0.27 & 0.18 \\
\hline $\mathrm{Na}_{2} \mathrm{O}$ & 0.37 & 0.03 & 0.39 & 0.02 & 0.37 & 0.03 & 0.39 & 0.02 & 0.38 & 0.10 & 0.41 & 0.02 \\
\hline $\mathrm{P}_{2} \mathrm{O}_{5}$ & 40.5 & 0.5 & 40.8 & 0.3 & 40.8 & 0.2 & 40.8 & 0.6 & 41.0 & 0.4 & 41.0 & 0.4 \\
\hline $\mathrm{Y}_{2} \mathrm{O}_{3}$ & n.d. & & n.d. & & n.d. & & n.d. & & n.d. & & n.d. & \\
\hline $\mathrm{Ce}_{2} \mathrm{O}_{3}$ & n.d. & & n.d. & & 0.05 & 0.02 & n.d. & & n.d. & & n.d. & \\
\hline $\mathrm{F}$ & 0.43 & 0.05 & 0.51 & 0.13 & 0.58 & 0.14 & 0.52 & 0.12 & 1.14 & 0.15 & 0.60 & 0.10 \\
\hline $\mathrm{Cl}$ & 5.29 & 0.22 & 5.32 & 0.19 & 5.09 & 0.23 & 5.02 & 0.33 & 3.91 & 0.19 & 5.05 & 0.19 \\
\hline$-\mathrm{O}=(\mathrm{F}+\mathrm{Cl})$ & 1.38 & 0.06 & 1.28 & 0.03 & 1.39 & 0.04 & 1.35 & 0.03 & 1.36 & 0.08 & 1.39 & 0.03 \\
\hline Total & 98.8 & 1.0 & 99.2 & 0.7 & 99.2 & 0.4 & 99.7 & 1.4 & 98.8 & 0.7 & 99.7 & 0.9 \\
\hline \multicolumn{13}{|c|}{ formula based on 13 anions } \\
\hline $\mathrm{Ca}$ & 4.92 & 0.03 & 4.95 & 0.02 & 4.96 & 0.02 & 4.99 & 0.03 & 4.91 & 0.05 & 4.96 & 0.03 \\
\hline $\mathrm{Mg}$ & 0.01 & 0.01 & n.d. & & 0.00 & 0.00 & 0.00 & 0.00 & 0.02 & 0.02 & 0.00 & 0.00 \\
\hline $\mathrm{Fe}$ & 0.06 & 0.04 & 0.02 & 0.01 & 0.02 & 0.01 & 0.02 & 0.01 & 0.04 & 0.03 & 0.02 & 0.01 \\
\hline $\mathrm{Na}$ & 0.06 & 0.01 & 0.07 & 0.00 & 0.06 & 0.00 & 0.07 & 0.00 & 0.06 & 0.02 & 0.07 & 0.00 \\
\hline $\mathrm{P}$ & 2.99 & 0.01 & 3.00 & 0.01 & 2.99 & 0.01 & 2.98 & 0.01 & 3.00 & 0.01 & 2.99 & 0.01 \\
\hline $\mathrm{Y}$ & n.d. & & n.d. & & n.d. & & n.d. & & n.d. & & n.d. & \\
\hline $\mathrm{Ce}$ & n.d. & & n.d. & & 0.00 & 0.00 & n.d. & & n.d. & & n.d. & \\
\hline $\mathrm{F}$ & 0.12 & 0.01 & 0.14 & 0.03 & 0.16 & 0.04 & 0.14 & 0.03 & 0.31 & 0.04 & 0.16 & 0.03 \\
\hline $\mathrm{Cl}$ & 0.78 & 0.03 & 0.78 & 0.03 & 0.75 & 0.04 & 0.73 & 0.06 & 0.57 & 0.03 & 0.74 & 0.03 \\
\hline Other $^{1}$ & 0.10 & 0.04 & 0.08 & 0.02 & 0.09 & 0.03 & 0.13 & 0.03 & 0.12 & 0.05 & 0.10 & 0.03 \\
\hline Total & 8.94 & 0.04 & 8.96 & 0.02 & 8.95 & 0.03 & 8.94 & 0.03 & 8.92 & 0.06 & 8.94 & 0.02 \\
\hline $\mathrm{Cl} / \mathrm{F}^{2}$ & 6.64 & 0.85 & 6.08 & 2.10 & 5.03 & 1.52 & 5.54 & 1.69 & 1.87 & 0.27 & 4.70 & 0.99 \\
\hline $\mathrm{Cl} \#^{3}$ & 86.8 & 1.4 & 84.9 & 3.6 & 82.5 & 4.1 & 83.9 & 4.0 & 64.8 & 3.2 & 82.0 & 3.1 \\
\hline$n^{4}$ & 18 & & 18 & & 16 & & 6 & & 17 & & 20 & \\
\hline
\end{tabular}

n.d. = not detected (detection limits: $0.02 \mathrm{wt} \%$ for $\mathrm{MgO}, 0.04 \mathrm{wt} \%$ for $\mathrm{Y}_{2} \mathrm{O}_{3}, 0.05 \mathrm{wt} \%$ for $\mathrm{Ce}_{2} \mathrm{O}_{3}$ ) 


\section{Page 23 of 39}

\section{Running Head}

1 5

7

8

9

11

13

14

15

16

17

18

19

20

21

22

23

24

25

26

27

28

29

30

31

32

33

34

35

36

37

38

39

40

41

42

43

44

45

46

47

48

${ }^{1}$ missing component calculated by difference: Other $=1-(\mathrm{Cl}+\mathrm{F})$, not included in the total

${ }^{2}$ atomic ratio

${ }^{3} \mathrm{Cl} \#=\mathrm{Cl} /(\mathrm{Cl}+\mathrm{F}) \times 100$, atomic

${ }^{4} \mathrm{n}=$ number of analyses 
Table 4. Average merrillite compositions.

\begin{tabular}{|c|c|c|c|c|c|c|c|c|c|c|c|c|}
\hline & \multicolumn{2}{|c|}{ Santa Barbara } & \multicolumn{2}{|c|}{ Elenovka } & \multicolumn{2}{|c|}{ Bruderheim } & \multicolumn{6}{|c|}{ Kendleton } \\
\hline & L4 & $1 \sigma$ & L5 & $1 \sigma$ & L6 & $1 \sigma$ & L3 clast & $1 \sigma$ & L4 host & $1 \sigma$ & L5 clast & $1 \sigma$ \\
\hline $\mathrm{CaO}$ & 46.3 & 0.7 & 46.5 & 0.4 & 46.6 & 0.1 & 46.4 & 0.1 & 46.1 & 0.3 & 46.6 & 0.2 \\
\hline $\mathrm{MgO}$ & 3.44 & 0.09 & 3.47 & 0.15 & 3.46 & 0.04 & 3.50 & 0.04 & 3.48 & 0.04 & 3.58 & 0.05 \\
\hline $\mathrm{FeO}$ & 1.05 & 0.66 & 0.56 & 0.18 & 0.57 & 0.24 & 0.45 & 0.10 & 0.74 & 0.37 & 0.58 & 0.29 \\
\hline $\mathrm{Na}_{2} \mathrm{O}$ & 2.57 & 0.22 & 2.66 & 0.12 & 2.67 & 0.03 & 2.83 & 0.02 & 2.63 & 0.05 & 2.83 & 0.05 \\
\hline $\mathrm{P}_{2} \mathrm{O}_{5}$ & 45.6 & 0.6 & 45.5 & 0.4 & 45.6 & 0.2 & 45.8 & 0.4 & 45.6 & 0.2 & 45.8 & 0.2 \\
\hline $\mathrm{Y}_{2} \mathrm{O}_{3}$ & 0.04 & 0.02 & n.d. & & 0.04 & 0.02 & 0.04 & 0.03 & n.d. & & n.d. & \\
\hline $\mathrm{Ce}_{2} \mathrm{O}_{3}$ & n.d. & & n.d. & & 0.05 & 0.02 & n.d. & & n.d. & & n.d. & \\
\hline Total & 99.0 & 0.9 & 98.8 & 0.6 & 98.9 & 0.4 & 99.0 & 0.6 & 98.7 & 0.5 & 99.5 & 0.3 \\
\hline \multicolumn{13}{|c|}{ formula based on 56 oxygens } \\
\hline $\mathrm{Ca}$ & 18.0 & 0.1 & 18.1 & 0.1 & 18.1 & 0.1 & 18.0 & 0.1 & 17.9 & 0.1 & 18.0 & 0.1 \\
\hline $\mathrm{Mg}$ & 1.86 & 0.05 & 1.87 & 0.09 & 1.87 & 0.02 & 1.88 & 0.03 & 1.88 & 0.02 & 1.92 & 0.03 \\
\hline $\mathrm{Fe}$ & 0.32 & 0.20 & 0.17 & 0.05 & 0.17 & 0.07 & 0.14 & 0.03 & 0.22 & 0.11 & 0.18 & 0.09 \\
\hline $\mathrm{Na}$ & 1.80 & 0.15 & 1.87 & 0.08 & 1.88 & 0.02 & 1.98 & 0.01 & 1.85 & 0.04 & 1.98 & 0.03 \\
\hline $\mathrm{P}$ & 14.0 & 0.1 & 14.0 & 0.0 & 14.0 & 0.0 & 14.0 & 0.0 & 14.0 & 0.0 & 14.0 & 0.0 \\
\hline $\mathrm{Y}$ & 0.01 & 0.00 & n.d. & & 0.01 & 0.00 & 0.01 & 0.01 & n.d. & & n.d. & \\
\hline $\mathrm{Ce}$ & n.d. & & n.d. & & 0.01 & 0.00 & n.d. & & n.d. & & n.d. & \\
\hline Total & 35.9 & 0.1 & 36.0 & 0.1 & 36.0 & 0.0 & 36.0 & 0.0 & 35.9 & 0.1 & 36.0 & 0.1 \\
\hline $\mathrm{Mg \#}^{1}$ & 86.0 & 7.4 & 91.7 & 2.2 & 91.6 & 3.1 & 93.3 & 1.4 & 89.6 & 4.6 & 91.8 & 3.5 \\
\hline$n^{2}$ & 22 & & 12 & & 15 & & 6 & & 14 & 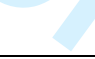 & 23 & \\
\hline \multicolumn{13}{|c|}{ n.d. $=$ not detected (detection limits: $0.04 \mathrm{wt} \%$ for $\mathrm{Y}_{2} \mathrm{O}_{3}, 0.05 \mathrm{wt} \%$ for $\mathrm{Ce}_{2} \mathrm{O}_{3}$ ) } \\
\hline
\end{tabular}


Table 5. Average feldspar compositions.

\begin{tabular}{|c|c|c|c|c|c|c|c|c|c|c|}
\hline & \multicolumn{2}{|c|}{ Santa Barbara } & \multicolumn{2}{|c|}{ Kramer Creek } & \multicolumn{2}{|c|}{ Elenovka } & \multicolumn{2}{|c|}{ Roy 1933} & \multicolumn{2}{|c|}{ Bruderheim } \\
\hline & L4 & $1 \sigma$ & L4 & $1 \sigma$ & L5 & $1 \sigma$ & L5 & $1 \sigma$ & L6 & $1 \sigma$ \\
\hline $\mathrm{SiO}_{2}$ & 62.0 & 6.5 & 54.2 & 9.4 & 66.2 & 0.4 & 65.5 & 1.0 & 66.0 & 0.5 \\
\hline $\mathrm{Al}_{2} \mathrm{O}_{3}$ & 23.3 & 4.1 & 28.6 & 6.6 & 21.2 & 0.2 & 21.0 & 0.6 & 21.3 & 0.3 \\
\hline $\mathrm{Cr}_{2} \mathrm{O}_{3}$ & 0.30 & 0.63 & 0.21 & 0.27 & n.d. & & n.d. & & n.d. & \\
\hline $\mathrm{FeO}$ & 1.03 & 0.72 & 0.55 & 0.30 & 0.46 & 0.14 & 0.42 & 0.26 & 0.52 & 0.16 \\
\hline $\mathrm{MgO}$ & 0.16 & 0.24 & 0.04 & 0.03 & 0.04 & 0.16 & 0.05 & 0.08 & n.d. & \\
\hline $\mathrm{CaO}$ & 4.38 & 4.79 & 10.7 & 7.5 & 2.15 & 0.14 & 2.09 & 0.61 & 2.19 & 0.10 \\
\hline $\mathrm{Na}_{2} \mathrm{O}$ & 8.75 & 2.66 & 5.48 & 4.32 & 10.00 & 0.16 & 9.58 & 1.50 & 9.80 & 0.36 \\
\hline $\mathrm{K}_{2} \mathrm{O}$ & 1.03 & 0.99 & 0.14 & 0.15 & 1.04 & 0.20 & 1.38 & 2.32 & 1.00 & 0.16 \\
\hline Total & 100.9 & 0.9 & 99.9 & 0.5 & 101.1 & 0.6 & 100.1 & 0.7 & 100.9 & 0.6 \\
\hline \multicolumn{11}{|c|}{ formula based on 8 oxygens } \\
\hline $\mathrm{Si}$ & 2.74 & 0.25 & 2.45 & 0.37 & 2.90 & 0.01 & 2.89 & 0.03 & 2.89 & 0.01 \\
\hline $\mathrm{Al}$ & 1.22 & 0.24 & 1.53 & 0.38 & 1.09 & 0.01 & 1.10 & 0.03 & 1.10 & 0.01 \\
\hline $\mathrm{Cr}$ & 0.01 & 0.02 & 0.01 & 0.01 & n.d. & & n.d. & & n.d. & \\
\hline $\mathrm{Fe}$ & 0.04 & 0.03 & 0.02 & 0.01 & 0.02 & 0.01 & 0.02 & 0.01 & 0.02 & 0.01 \\
\hline $\mathrm{Mg}$ & 0.01 & 0.02 & 0.00 & 0.00 & 0.00 & 0.01 & 0.00 & 0.01 & n.d. & \\
\hline $\mathrm{Ca}$ & 0.21 & 0.24 & 0.53 & 0.37 & 0.10 & 0.01 & 0.10 & 0.03 & 0.10 & 0.00 \\
\hline $\mathrm{Na}$ & 0.75 & 0.22 & 0.47 & 0.37 & 0.85 & 0.01 & 0.82 & 0.13 & 0.83 & 0.03 \\
\hline K & 0.06 & 0.06 & 0.01 & 0.01 & 0.06 & 0.01 & 0.08 & 0.14 & 0.06 & 0.01 \\
\hline Total & 5.04 & 0.02 & 5.02 & 0.01 & 5.01 & 0.01 & 5.01 & 0.01 & 5.00 & 0.02 \\
\hline An & 20.9 & 23.6 & 52.2 & 37.0 & 10.0 & 0.6 & 9.9 & 2.9 & 10.4 & 0.6 \\
\hline $\mathrm{Ab}$ & 73.4 & 21.5 & 47.0 & 36.2 & 84.2 & 1.2 & 82.1 & 12.5 & 84.0 & 1.1 \\
\hline Or & 5.7 & 5.5 & 0.8 & 0.8 & 5.8 & 1.1 & 7.9 & 13.6 & 5.6 & 1.0 \\
\hline $\mathrm{n}^{1}$ & 43 & & 41 & & 81 & & 38 & & 25 & \\
\hline
\end{tabular}


Fig. 1. Thin sections of samples studied: images on the left are flat-bed optical scans of (a) Santa Barbara (L4), (b) Elenovka (L5), (c) Bruderheim (L6). Maps on the right show the distribution of merrillite (red) and apatite (blue) in selected regions of each thin section. Phosphate distributions were generated using WDS element maps, see text for details.

Fig. 1 (cont.). Thin sections of samples studied: images on the left are flat-bed optical scans the L regolith breccia Kendleton's (d) L3 clast, (e) L4 host, (f) L5 clast. Maps on the right show the distribution of merrillite (red) and apatite (blue) in selected regions of each thin section. Phosphate distributions were generated using WDS element maps, see text for details.

Fig. 2. BSE images of apatite in L chondrites. (a,b) Santa Barbara (L4) illustrating (a) fine-grained apatite (Ap) and feldspar (Fsp) with olivine (Ol) and (b) an apatite and merrillite (Merr) intergrowth with olivine and low-Ca pyroxene (Px). (c,d) Elenovka (L5) illustrating apatite occurring adjacent to voids, in association with troilite (Tro), olivine, pyroxene, and feldspar. (e,f) Bruderheim (L6) illustrating (e) apatite adjacent to a void with an olivine inclusion and adjacent feldspar, pyroxene, and olivine and (f) large apatite grain occurring with feldspar, olivine, and pyroxene.

Fig. 3. BSE images of merrillite in L chondrites. (a,b) Santa Barbara (L4) illustrating (a) large merrillite (Merr) grain with inclusions of olivine (Ol), feldspar (Fsp), chromite (Chr), and troilite (Tro), adjacent to olivine, pyroxene (Px), feldspar and a void and (b) merrillite and pyroxene enclosed by Fe,Ni metal (Fe,Ni), chromite and troilite. (c,d) Elenovka (L5) illustrating (c) merrillite adjacent to troilite, pyroxene, olivine, and feldspar and blown up portion (d) showing inclusions of feldspar and olivine. (e,f)

Bruderheim (L6) illustrating (e) merrillite adjacent to Fe,Ni metal, olivine, pyroxene, and minor feldspar and (f) merrillite associated with chromite-plagioclase assemblage.

Fig. 4. BSE images of apatite and merrillite in the L regolith breccia Kendleton. (a,b) L3 clast illustrating (a) small apatite (Ap) grain in olivine (Ol) with minor feldspar (Fsp) and (b) merrillite (Merr) inclusions in $\mathrm{Fe}, \mathrm{Ni}$ metal $(\mathrm{Fe}, \mathrm{Ni})$ : merrillite is surrounded by Ni-rich halos. (c,d) L4 host material illustrating (c) apatite and merrillite intergrowth with adjacent pyroxene (Px), feldspar, and troilite (Tro) and (d) veinfilling apatite in and around olivine grain. (e,f) L5 clast illustrating (e) large apatite-merrillite intergrowth with inclusions of feldspar and (f) apatite-merrillite intergrowth with adjacent Fe,Ni metal, troilite, olivine, pyroxene, and feldspar.

Fig. 5. Atomic Cl-F-Other anion ternaries from EPMA analysis of apatite in (a) non-brecciated L chondrites and (b) the $\mathrm{L}$ regolith breccia Kendleton. Each point represents a single analysis. The ternaries are truncated at $\mathrm{Cl}=0.4$. The non-brecciated chondrites have similar Cl-rich compositions. Kendleton has lithology-dependent apatite compositions where the L4 host shows significant F-enrichment over the L3 and L5 clasts which are similar to the non-brecciated L chondrites.

Fig. 6. Histograms of atomic $\mathrm{Mg \#}(\mathrm{Mg} /(\mathrm{Mg}+\mathrm{Fe}) \times 100)$ from individual EPMA analyses of merrillite in $\mathrm{H}$, $\mathrm{L}$, LL OCs and the $\mathrm{L}$ regolith breccia Kendleton. $\mathrm{Mg \#}$ is binned into $1 \%$ bins and the diamond and thin line show the sample mean.

Fig. 7. BSE images of occurrences of feldspar within relict chondrules in L chondrites. (a-d) Santa Barbara (L4) illustrating (a) POP chondrule with (b) anorthitic plagioclase (An) containing submicron oxides and micropores, surrounded by albitic $(\mathrm{Ab})$ rims; (c) POP chondrule with (d) albitic plagioclase showing K-feldspar exsolution. (e,f) Kramer Creek (L4) illustrating (e) BO chondrule containing (f) anorthitic plagioclase with dissolution lamellae and minor albite along the rims. 
Fig. 7 (cont.). BSE images of occurrences of feldspar within relict chondrules in L chondrites. (g,h) Elenovka (L5) illustrating (g) relict BO chondrule containing (h) albitic plagioclase with minor Kfeldspar exsolution that occurs both within the grain and around the rim of a void. (i,j) Roy 1933 (L5) illustrating (i) relict POP chondrule with (j) albitic plagioclase and K-feldspar exsolution. (k,l) Bruderheim (L6) illustrating (k) relict POP chondrule with (l) typical uniform albitic plagioclase.

Fig. 8. Feldspar compositions in L ordinary chondrites from EPMA analysis: (a) Santa Barbara (L4), (b) Kramer Creek (L4), Elenovka (L5), (d) Roy 1033 (L5), and (e) Bruderheim (L6). Each point represents a single analysis and each color represents a single chondrule.

Fig. 9. Apatite atomic Cl-F-Other anion ternary diagram, for $\mathrm{H}$ (red), L (green), and LL (blue) OCs. Each point represents a single analysis and each field encloses all the analyses in that group. Bulk chondrite $\mathrm{Cl} / \mathrm{F}$ ratios from Wasson and Kallemeyn (1988) for OCs and CI chondrites are illustrated as tie-lines from the Cl-F ternary join to the Other apex.

Fig. 10. Mean $\mathrm{Cl} \#$ (atomic $\mathrm{Cl} /(\mathrm{Cl}+\mathrm{F}) \times 100)$ for individual non-brecciated and brecciated OCs. Data are from the following sources: H chondrites, Jones and McCubbin (2012); L chondrites, this study; LL chondrites, Jones et al. (2014); Zag H4-6 breccia, Jones et al. (2011). Error bars represent $\pm 1 \sigma$. Bulk Cl\# values for OCs and CI chondrites from Wasson and Kallemeyn (1988) and Lodders and Fegley (1998) are shown for comparison.

\section{Supporting information}

Table S1. EPMA analyses of apatite from type 4-6 L chondrites.

Table S2. EPMA analyses of merrillite from type 4-6 L chondrites.

Table S3. EPMA analyses of feldspar from type 4-6 L chondrites. 


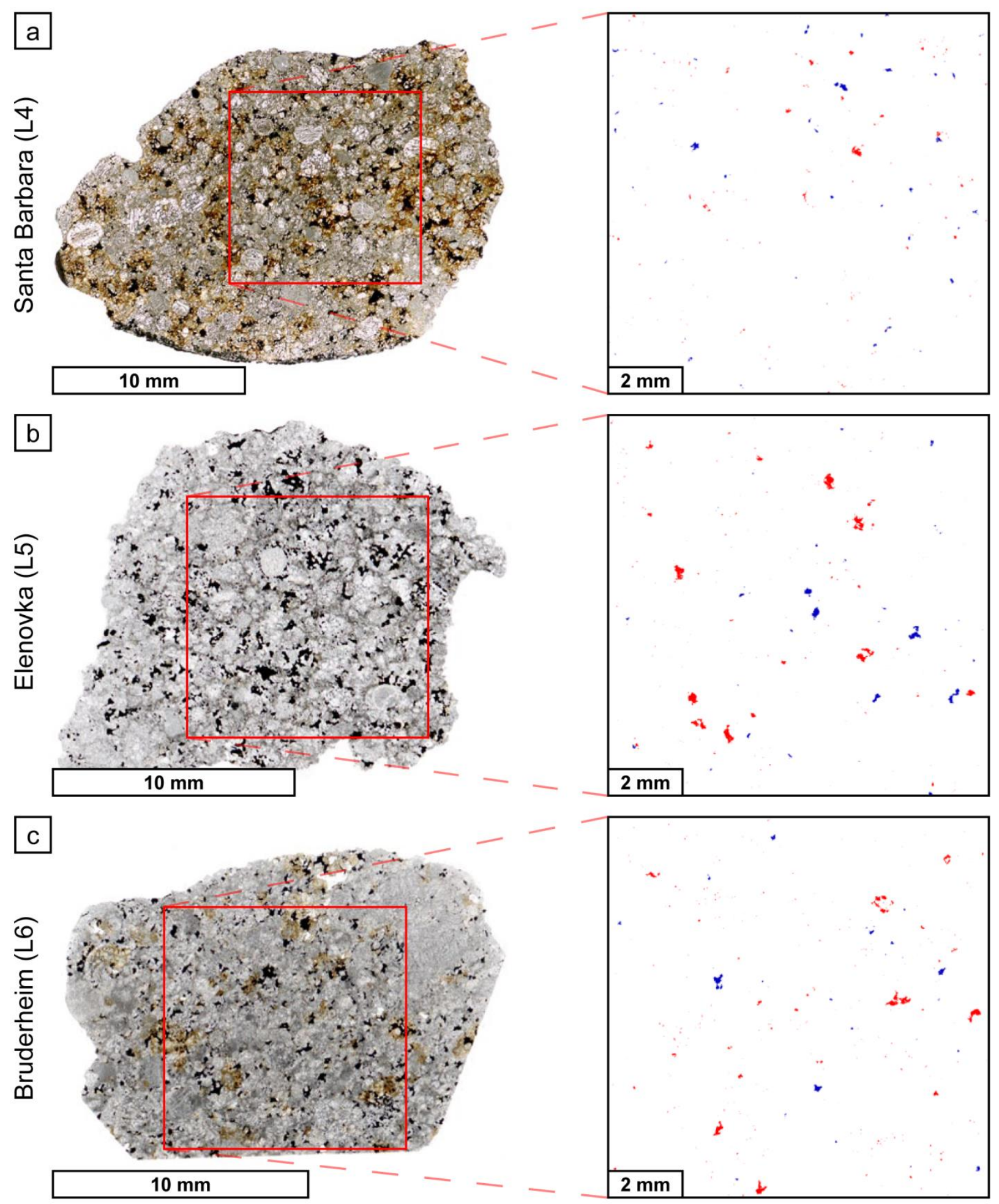

Fig. 1. Thin sections of samples studied: images on the left are flat-bed optical scans of (a) Santa Barbara (L4), (b) Elenovka (L5), (c) Bruderheim (L6). Maps on the right show the distribution of merrillite (red) and apatite (blue) in selected regions of each thin section. Phosphate distributions were generated using WDS element maps, see text for details. 

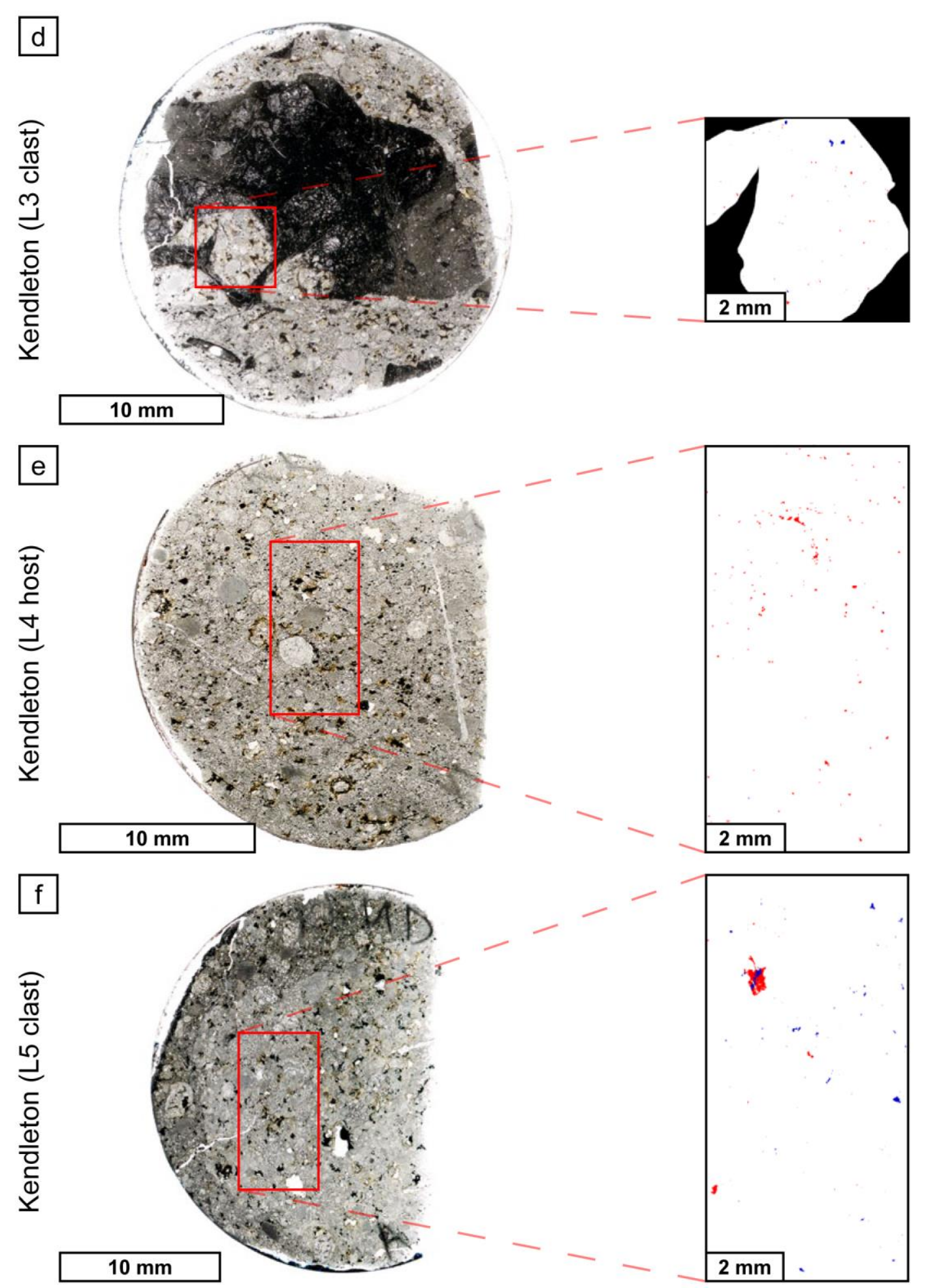

Fig. 1 (cont.). Thin sections of samples studied: images on the left are flat-bed optical scans the L regolith breccia Kendleton's (d) L3 clast, (e) L4 host, (f) L5 clast. Maps on the right show the distribution of merrillite (red) and apatite (blue) in selected regions of each thin section. Phosphate distributions were generated using WDS element maps, see text for details. 

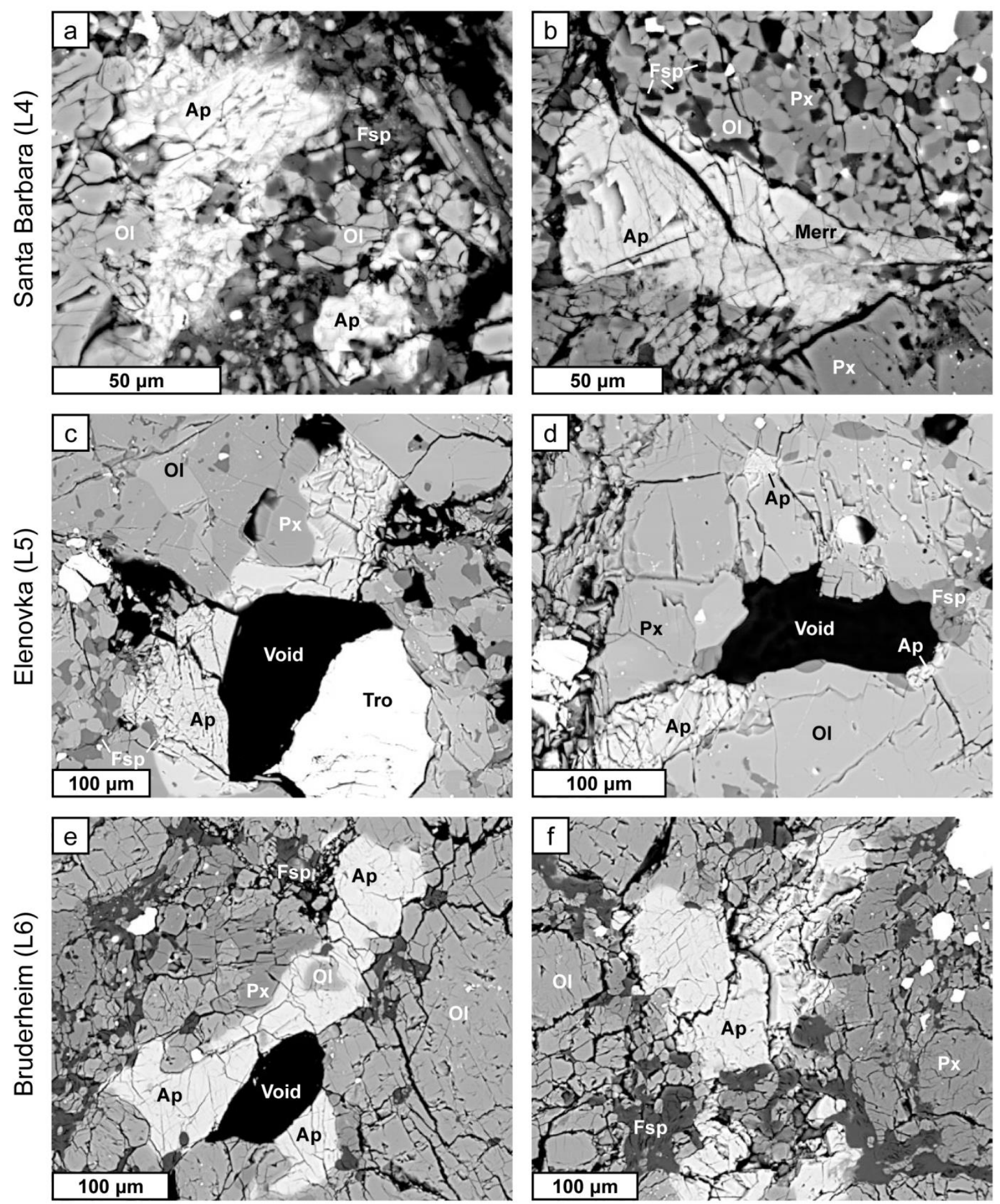

Fig. 2. BSE images of apatite in L chondrites. (a,b) Santa Barbara (L4) illustrating (a) fine-grained apatite (Ap) and feldspar (Fsp) with olivine (Ol) and (b) an apatite and merrillite (Merr) intergrowth with olivine and low-Ca pyroxene (Px). (c,d) Elenovka (L5) illustrating apatite occurring adjacent to voids, in association with troilite (Tro), olivine, pyroxene, and feldspar. (e,f) Bruderheim (L6) illustrating (e) apatite adjacent to a void with an olivine inclusion and adjacent feldspar, pyroxene, and olivine and (f) large apatite grain occurring with feldspar, olivine, and pyroxene. 

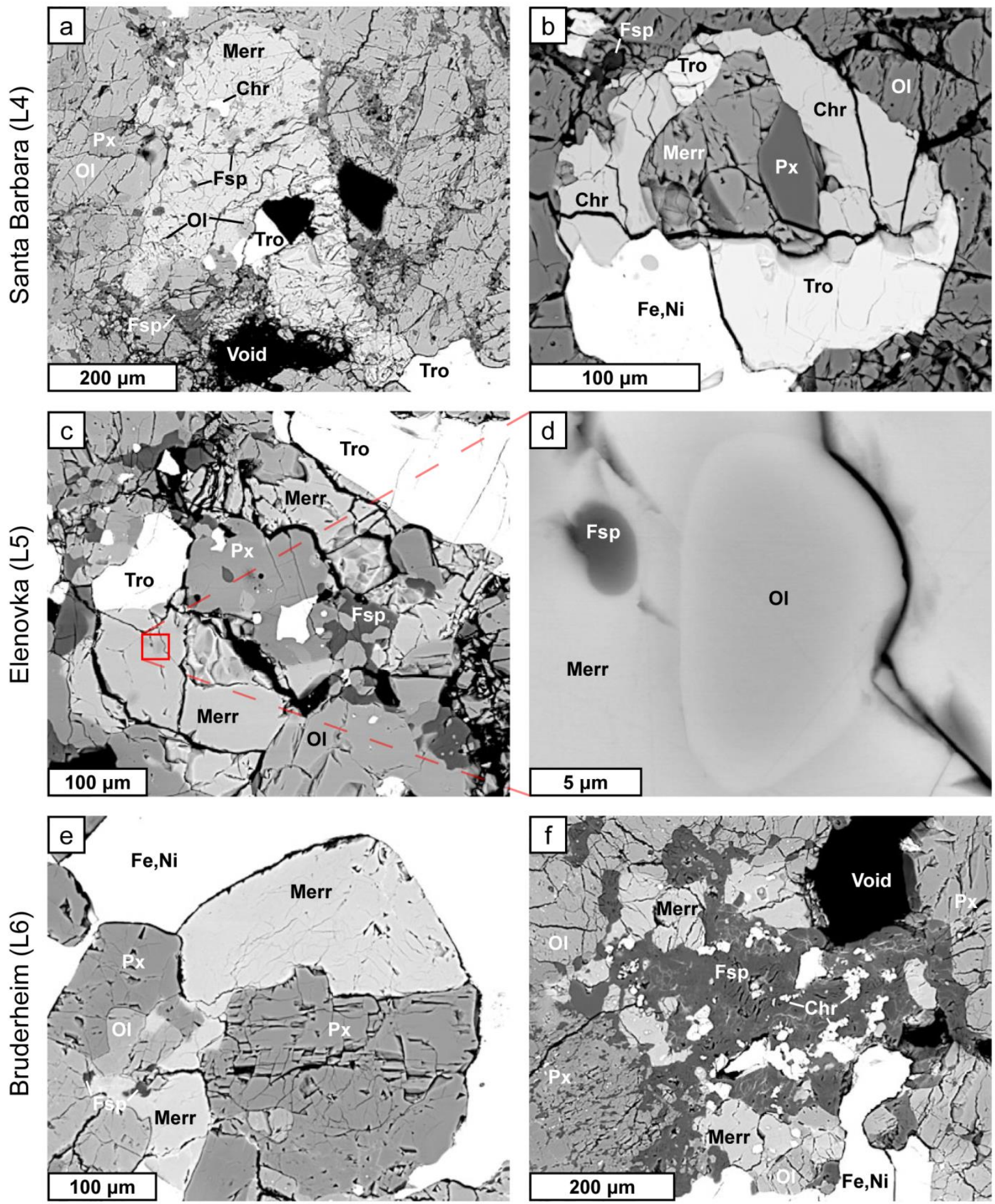

Fig. 3. BSE images of merrillite in L chondrites. (a,b) Santa Barbara (L4) illustrating (a) large merrillite (Merr) grain with inclusions of olivine (Ol), feldspar (Fsp), chromite (Chr), and troilite (Tro), adjacent to olivine, pyroxene (Px), feldspar and a void and (b) merrillite and pyroxene enclosed by Fe,Ni metal (Fe,Ni), chromite and troilite. (c,d) Elenovka (L5) illustrating (c) merrillite adjacent to troilite, pyroxene, olivine, and feldspar and blown up portion (d) showing inclusions of feldspar and olivine. (e,f) Bruderheim (L6) illustrating (e) merrillite adjacent to Fe,Ni metal, olivine, pyroxene, and minor feldspar and (f) merrillite associated with chromite-plagioclase assemblage. 

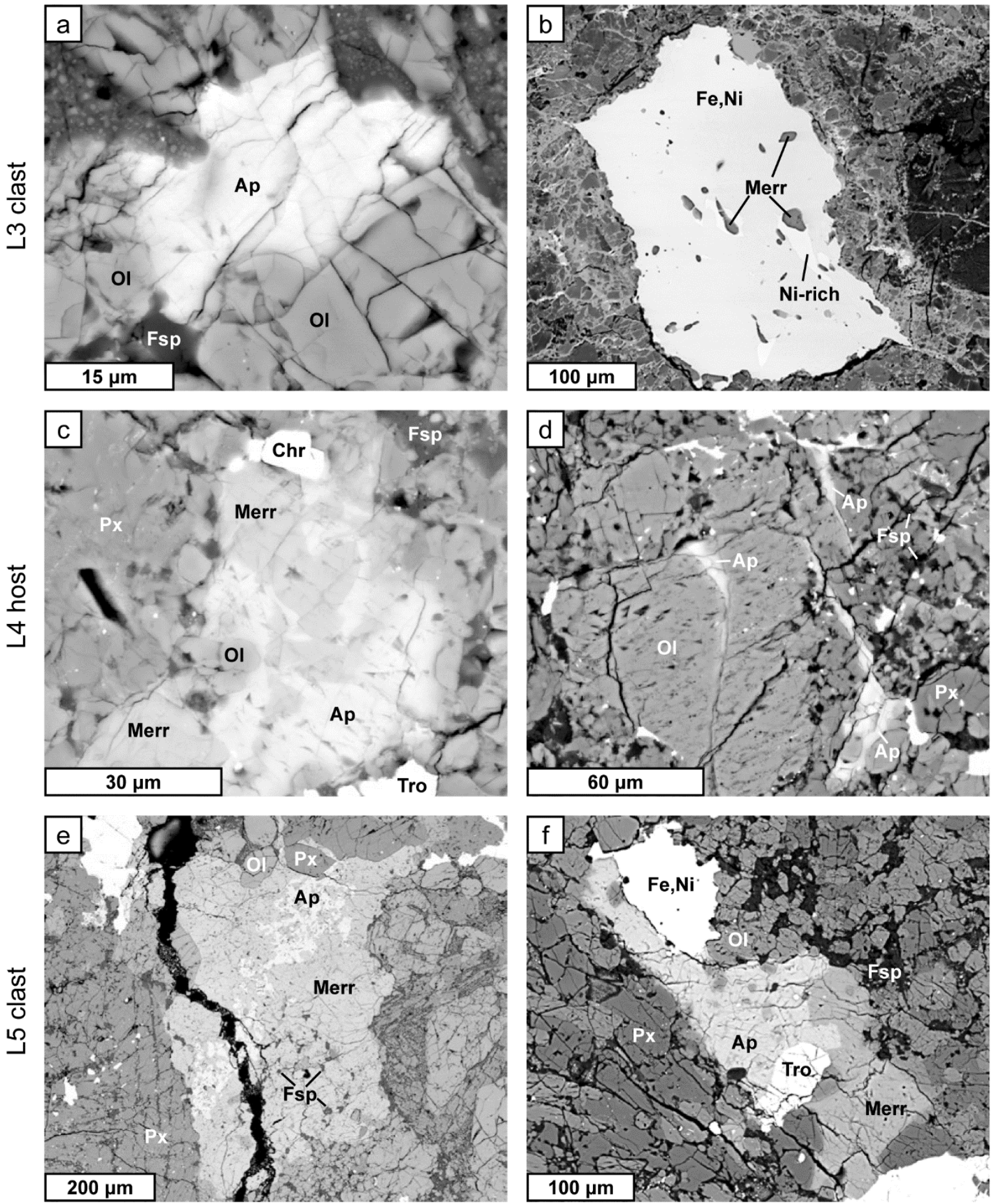

Fig. 4. BSE images of apatite and merrillite in the L regolith breccia Kendleton. (a,b) L3 clast illustrating (a) small apatite (Ap) grain in olivine (Ol) with minor feldspar (Fsp) and (b) merrillite (Merr) inclusions in Fe,Ni metal (Fe,Ni): merrillite is surrounded by Ni-rich halos. (c,d) L4 host material illustrating (c) apatite and merrillite intergrowth with adjacent pyroxene (Px), feldspar, and troilite (Tro) and (d) veinfilling apatite in and around olivine grain. (e,f) L5 clast illustrating (e) large apatite-merrillite intergrowth with inclusions of feldspar and (f) apatite-merrillite intergrowth with adjacent $\mathrm{Fe}, \mathrm{Ni}$ metal, troilite, olivine, pyroxene, and feldspar. 

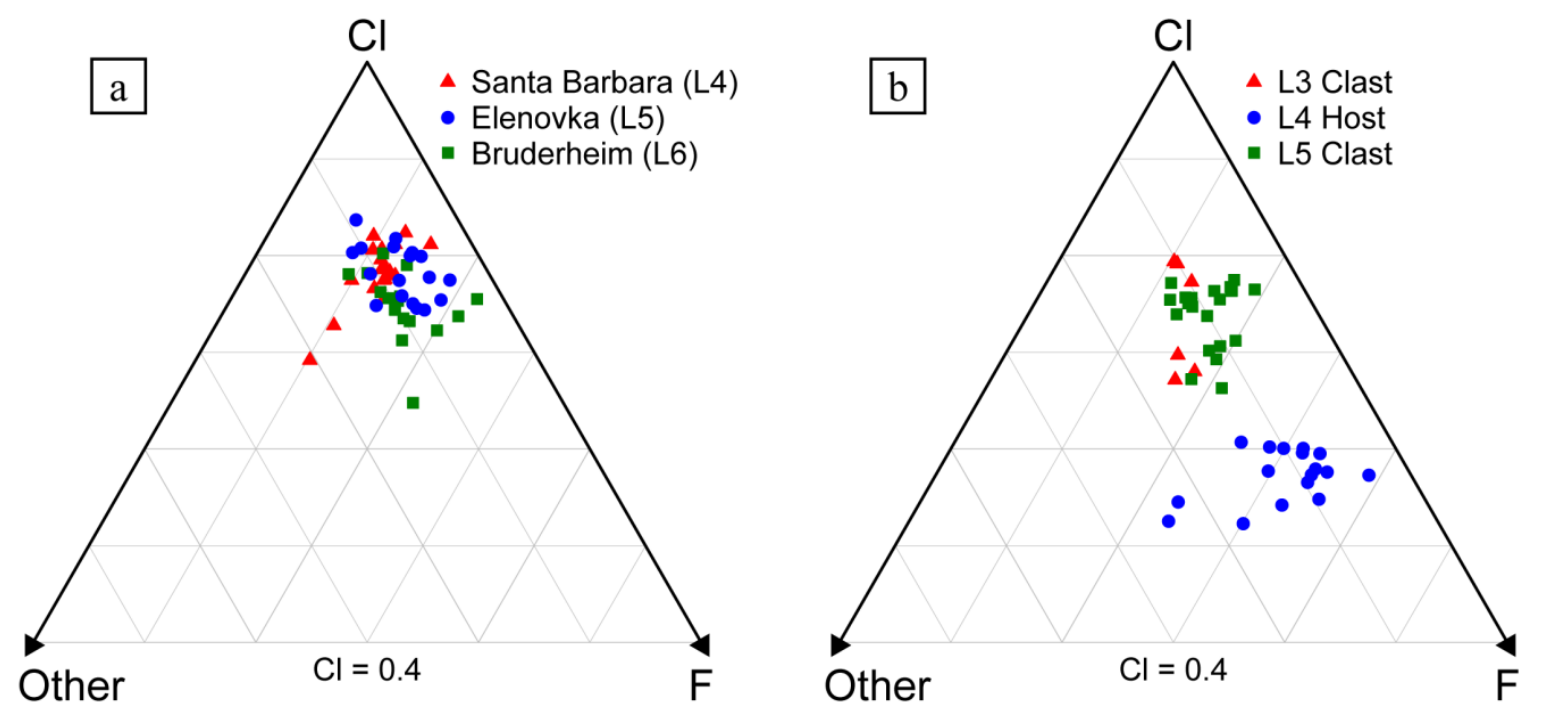

Fig. 5. Atomic Cl-F-Other anion ternaries from EPMA analysis of apatite in (a) non-brecciated L chondrites and (b) the $\mathrm{L}$ regolith breccia Kendleton. Each point represents a single analysis. The ternaries are truncated at $\mathrm{Cl}=0.4$. The non-brecciated chondrites have similar $\mathrm{Cl}$-rich compositions. Kendleton has lithology-dependent apatite compositions where the L4 host shows significant F-enrichment over the L3 and L5 clasts which are similar to the non-brecciated L chondrites. 


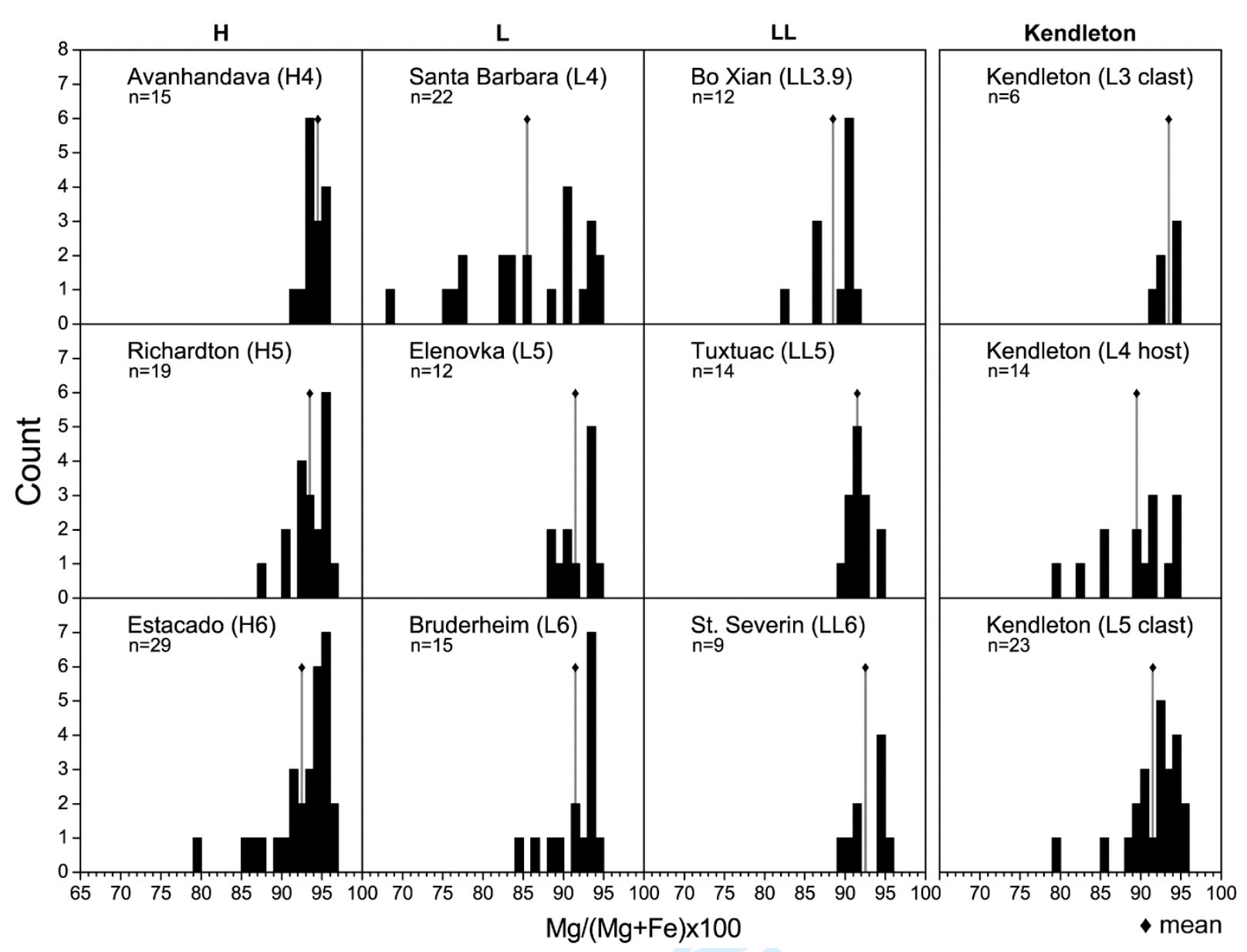

Fig. 6. Histograms of atomic $\mathrm{Mg \#}(\mathrm{Mg} /(\mathrm{Mg}+\mathrm{Fe}) \times 100)$ from individual EPMA analyses of merrillite in $\mathrm{H}$, $\mathrm{L}$, LL OCs and the L regolith breccia Kendleton. Mg\# is binned into 1\% bins and the diamond and thin line show the sample mean. 

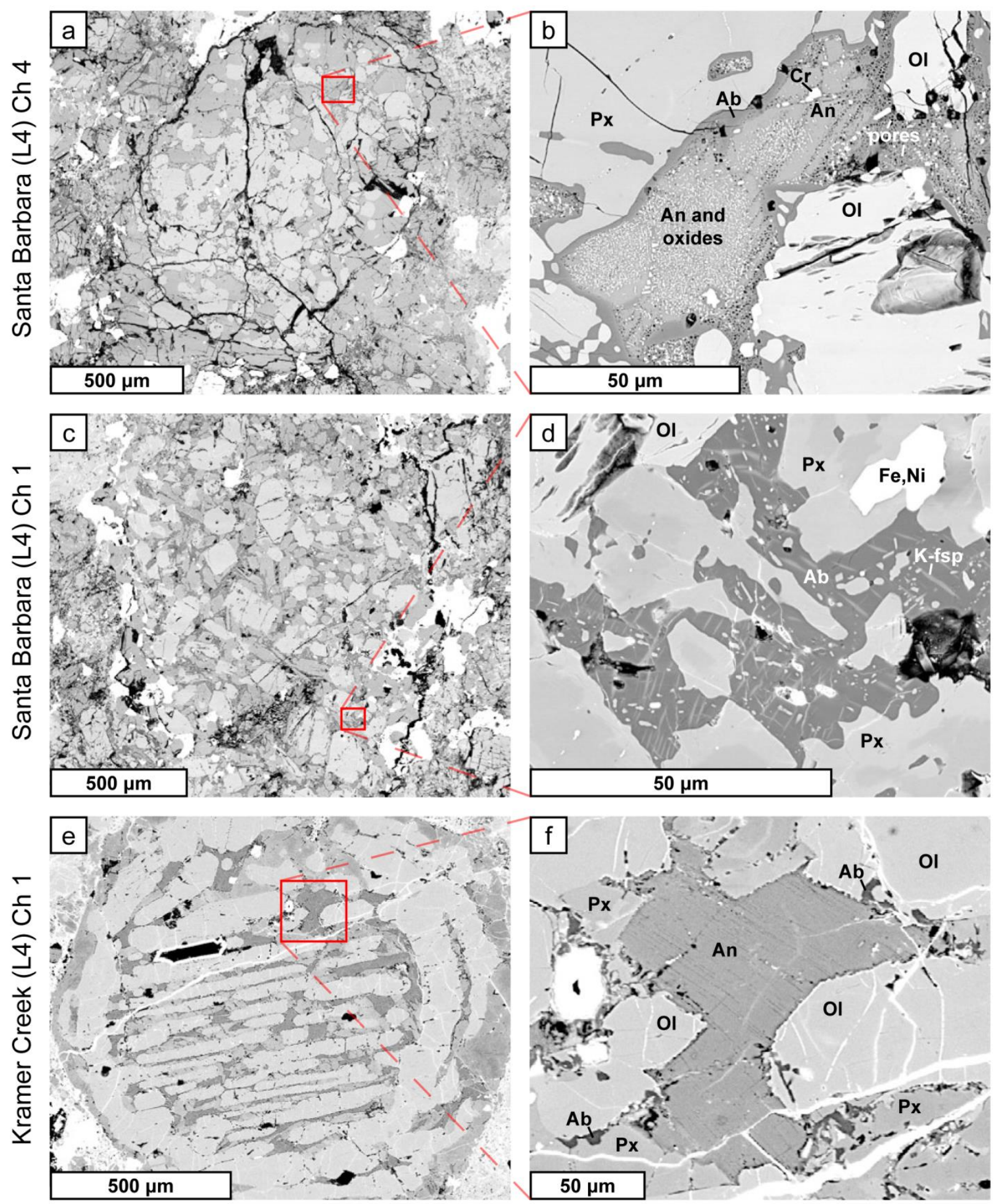

Fig. 7. BSE images of occurrences of feldspar within relict chondrules in L chondrites. (a-d) Santa Barbara (L4) illustrating (a) POP chondrule with (b) anorthitic plagioclase (An) containing submicron oxides and micropores, surrounded by albitic $(\mathrm{Ab})$ rims; (c) POP chondrule with (d) albitic plagioclase showing K-feldspar exsolution. (e,f) Kramer Creek (L4) illustrating (e) BO chondrule containing (f) anorthitic plagioclase with dissolution lamellae and minor albite along the rims. 

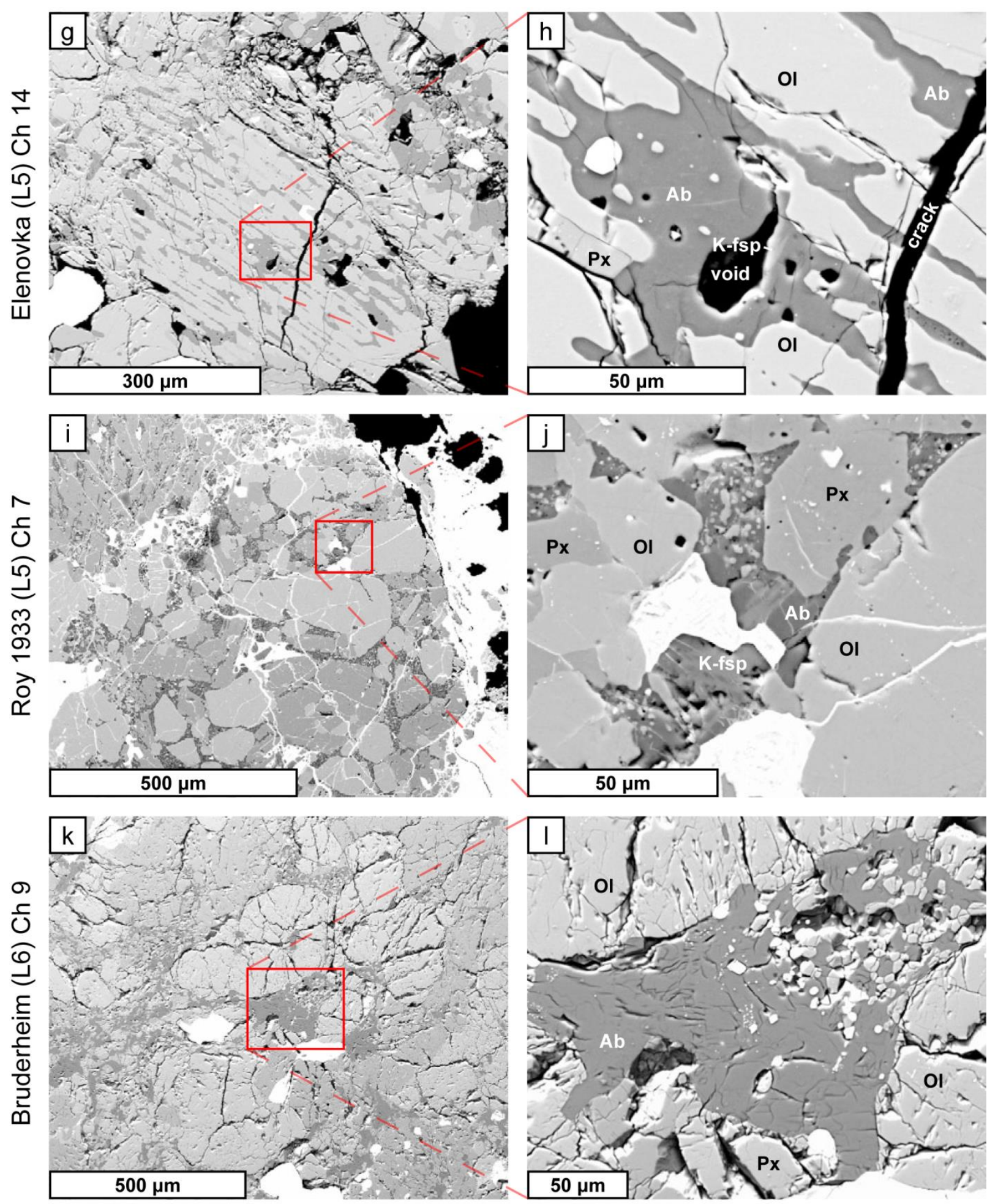

Fig. 7 (cont.). BSE images of occurrences of feldspar within relict chondrules in L chondrites. (g,h) Elenovka (L5) illustrating (g) relict BO chondrule containing (h) albitic plagioclase with minor Kfeldspar exsolution that occurs both within the grain and around the rim of a void. (i,j) Roy 1933 (L5) illustrating (i) relict POP chondrule with (j) albitic plagioclase and K-feldspar exsolution. (k,l) Bruderheim (L6) illustrating (k) relict POP chondrule with (l) typical uniform albitic plagioclase. 

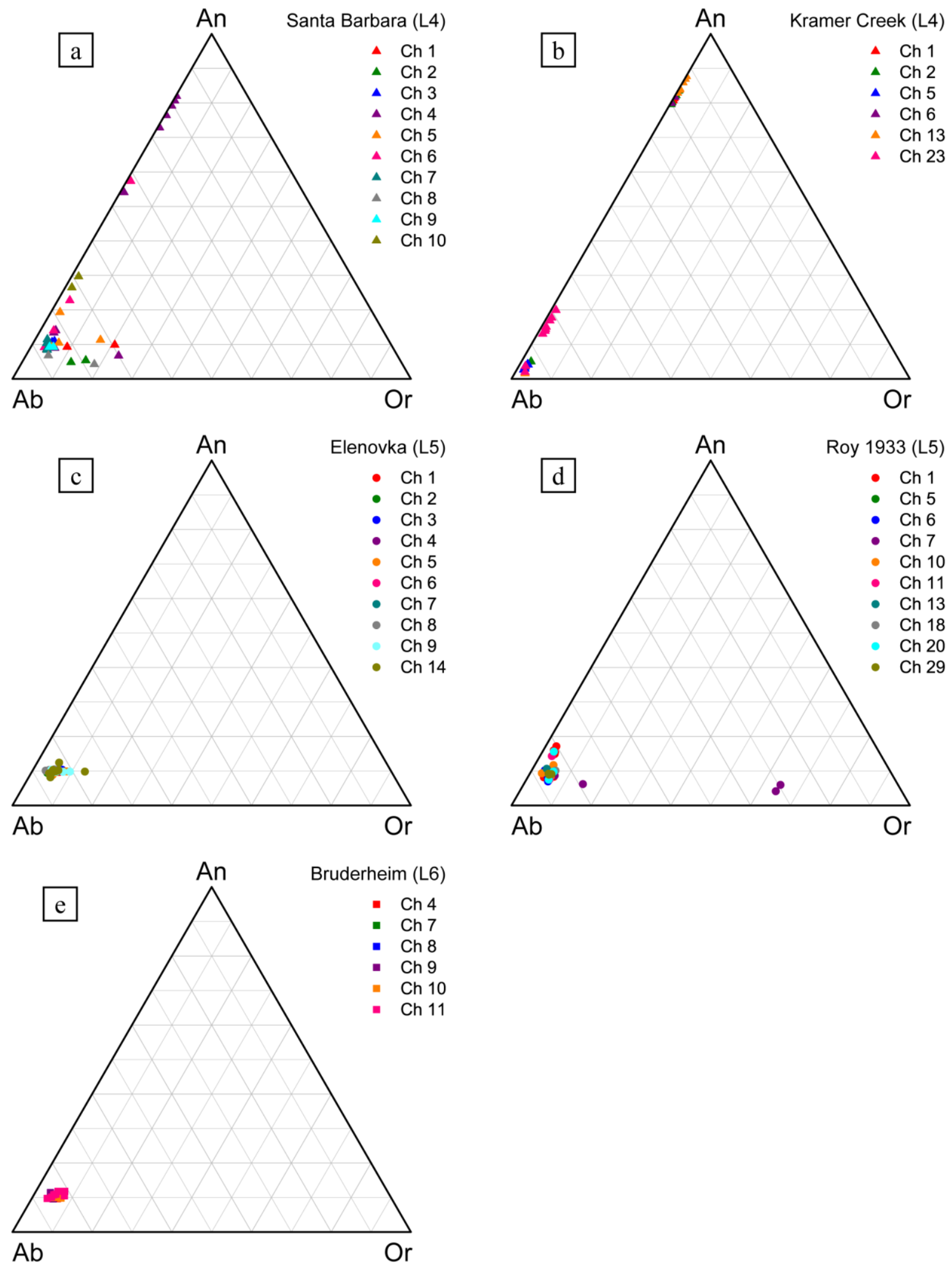

Fig. 8. Feldspar compositions in L ordinary chondrites from EPMA analysis: (a) Santa Barbara (L4), (b) Kramer Creek (L4), Elenovka (L5), (d) Roy 1033 (L5), and (e) Bruderheim (L6). Each point represents a single analysis and each color represents a single chondrule. 


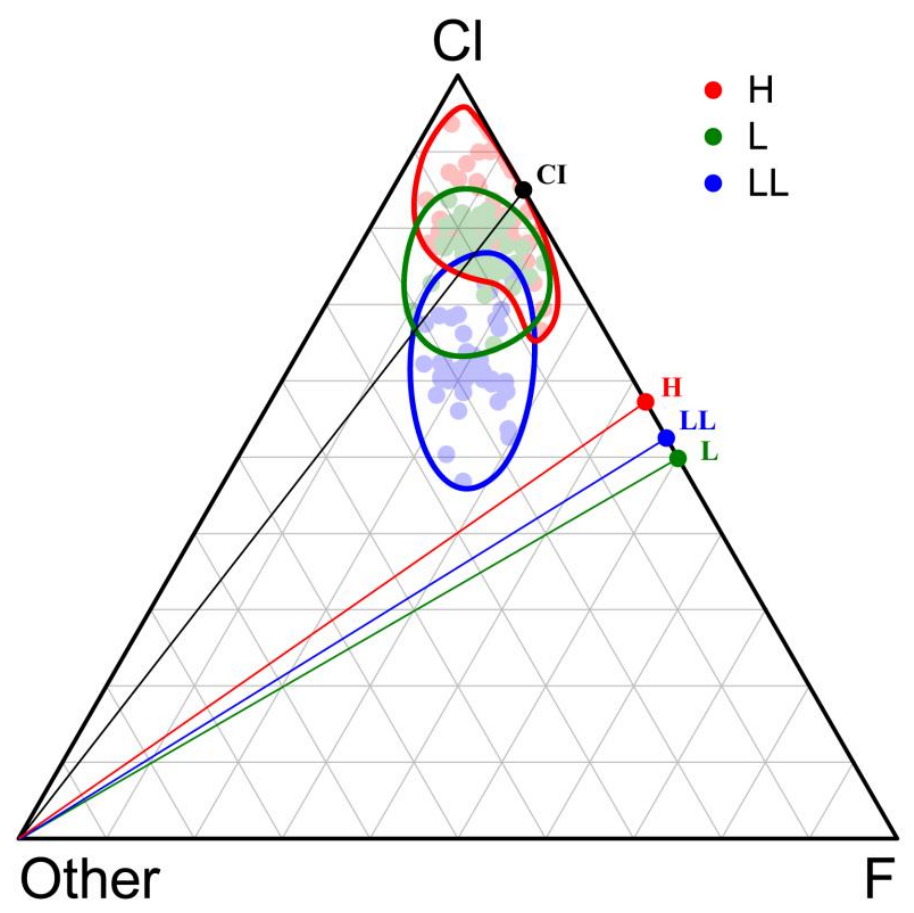

Fig. 9. Apatite atomic Cl-F-Other anion ternary diagram, for $\mathrm{H}$ (red), L (green), and LL (blue) OCs. Each point represents a single analysis and each field encloses all the analyses in that group. Bulk chondrite $\mathrm{Cl} / \mathrm{F}$ ratios from Wasson and Kallemeyn (1988) for OCs and CI chondrites are illustrated as tie-lines from the Cl-F ternary join to the Other apex. 
Fig. 10. Mean $\mathrm{Cl} \#$ (atomic $\mathrm{Cl} /(\mathrm{Cl}+\mathrm{F}) \times 100)$ for individual non-brecciated and brecciated OCs. Data are from the following sources: H chondrites, Jones and McCubbin (2012); L chondrites, this study; LL chondrites, Jones et al. (2014); Zag H4-6 breccia, Jones et al. (2011). Error bars represent $\pm 1 \sigma$. Bulk Cl\# values for OCs and CI chondrites from Wasson and Kallemeyn (1988) and Lodders and Fegley (1998) are shown for comparison. 